\title{
INTERACCIONES BIOCULTURALES DEL PUEBLO YAGÁN CON LAS MACROALGAS Y MOLUSCOS: UNA APROXIMACIÓN DESDE LA FILOSOFÍA AMBIENTAL DE CAMPO
}

\author{
JAIME OJEDA ${ }^{\mathrm{a}}, \mathrm{b}, \mathrm{RICARDO}$ ROZZI $^{\mathrm{b}, \mathrm{c}, \mathrm{f}}$, SEBASTIÁN ROSENFELD ${ }^{\mathrm{a}, \mathrm{b}}$ \\ TAMARA CONTADOR ${ }^{b, c}$, FRANCISCA MASSARDO ${ }^{b, c}, J^{2}$ JVIERA MALEBRÁN ${ }^{b, d}$, \\ JULIA GONZÁLEZ-CALDERÓNe \& ANDRÉS MANSILLA ${ }^{a, b}$
}

\section{RESUMEN}

Las zonas costeras de Magallanes poseen alta diversidad de macroalgas y moluscos. A su vez, han sido habitadas por pueblos originarios, como el pueblo yagán, que han desarrollado una variedad de interacciones bioculturales con los ecosistemas costeros. Este trabajo es un estudio interdisciplinario ecológico, etno-ecológico y filosófico que utiliza el marco conceptual de la ética biocultural para caracterizar el hábitat intermareal en el contexto biocultural del pueblo yagán a través de la composición de habitantes como macroalgas y moluscos, vinculado con hábitos estacionales de abundancia. Mediante esta caracterización se proponen métodos y actividades de conservación biocultural. Para ello, adaptamos la aproximación metodológica interdisciplinaria de la Filosofía Ambiental de Campo, en un estudio realizado en bahía Róbalo, isla Navarino (55S). Los resultados ecológicos mostraron que la biomasa y riqueza de macroalgas aumentó en verano y disminuyó en invierno; en contraste, los moluscos sésiles Mytilus edulis chilensis y Perumytilus purpuratus no presentaron una variabilidad estacional en su abundancia. Los resultados etnográficos basados en revisión de literatura y participación observante, muestran que la baja variabilidad estacional de la abundancia de moluscos ha sido vital para la subsistencia del pueblo yagán. Desde la perspectiva de la ética ambiental contemporánea identificamos diversos valores en la cosmovisión yagán. En un sentido amplio, identificamos un valor instrumental en los moluscos, que han sido utilizados por el pueblo yagán como fuente de alimentación, decoración estética, elaboración de herramientas y construcción de chozas. En las narrativas y otros registros etnográficos, identificamos un valor intrínseco, de los moluscos, arraigado en un profundo sentido de empatía. Para contribuir a la conservación biocultural, proponemos la metáfora "bosques sumergidos del Cabo de Hornos" y la actividad de campo "ojo buceo con ojo", que recuperan hábitos de encuentros experienciales con el hábitat intermareal y el conjuntos de sus cohabitantes.

PALABRAS CLAVE: Biocultural, ética ambiental, moluscos, macroalgas, yagán, conocimiento tradicional ecológico.

a Laboratorio de Ecosistemas Marinos Antárticos y Subantárticos (LEMAS), Casilla 113-D, Universidad de Magallanes, Punta Arenas, Chile. $\triangle$ jaimeojedavillarroel@yahoo.es; andres.mansilla@umag.cl; rosenfeld.sebastian@yahoo.com.

b Instituto de Ecología y Biodiversidad (IEB-Chile), Teniente Muñoz 396, Puerto Williams, Chile.

c Parque Etnobotánico Omora, Universidad de Magallanes, Teniente Muñoz 396, Puerto Williams, Chile. tamara.contador@ yahoo.com; massardorozzi@yahoo.com.

d Licenciatura en Ciencias Ambientales con Mención en Biología, Facultad de Ciencias, Universidad de Chile

Artesana de la Comunidad Indígena Yagán, Yelcho 218, Puerto Williams, Chile.

Department of Philosophy and Religion Studies, University of North Texas, Denton TX, USA. ricardo.rozzi@unt.edu 


\section{BIOCULTURAL INTERACTIONS OF THE YAGHAN PEOPLE WITH SEAWEEDS AND MOLLUSKS: FIELD ENVIRONMENTAL PHILOSOPHY APPROACH}

\section{ABSTRACT}

The coastal areas of the Magellan ecoregion host considerable diversity of macroalgae and mollusks. Indigenous peoples, such as the Yaghan, have developed biocultural interactions with austral coastal ecosystems. This study is an interdisciplinary ecological, ethnoecological and philosophical analysis. It applies the conceptual framework of biocultural ethics to characterize the intertidal habitat within the biocultural context of the Yaghan people. This is done through the composition of inhabitants, such as macroalgae and mollusks, linked to seasonal habits of abundance. Based on this account, we suggest methods and activities of biocultural conservations. We applied the Field Environmental Philosophy approach, which was carried out in Róbalo bay, Navarino island $\left(55^{\circ} \mathrm{S}\right)$. Ecological results showed that biomass and macroalgae diversity increased in summer and decreased over the winter. Mollusks Mytilus edulis chilensis and Perumytilus purpuratus showed no seasonal variability abundance. Ethnographic results based on the literature and observant participation showed that low seasonal variability in mollusk abundance has been crucial to the subsistence of the Yaghan people. From the perspective of contemporary environmental ethics, we identified several values in the Yaghan worldview. For example, there are instrumental values in mollusks: they have been a source of food, aesthetic decoration, development of tools and building huts. We found references to the intrinsic values in mollusks, particularly in narratives and other ethnographic sources. These Yaghan values are rooted in a profound sense of empathy for biodiversity. As a result of the combined ecological, ethnographic, and philosophical issues, we suggest communication through metaphor (the submerged forest of Cape Horn) and field activities (open your eyes, dive with an open mind) for biocultural conservation.

KEY WORDS: Biocultural, Environmental ethics, mollusks, macroalgae, Yaghan, traditional ecological knowledge.

\section{INTRODUCCIÓN}

La biosfera genera bienes y servicios ecosistémicos cuyo valor monetario se ha estimado en US\$33 billones de dólares/año, representando 1,8 veces el producto nacional bruto $(\mathrm{PNB})^{1}$ mundial (Costanza et al. 1997). Es decir, el valor económico que genera la biodiversidad casi duplica el valor económico de todos los bienes y servicios generados por la sociedad global. Dentro de una valoración monetaria de los servicios ecosistémicos globales, los ecosistemas costeros son esenciales para la ecología del planeta y para el bienestar social de la población humana. Los ecosistemas costeros, desde la zona intermareal hasta el quiebre de la plataforma continental, representan solo el

1 La diferencia entre producto interno bruto (PIB) y producto nacional bruto (PNB) depende de los límites de producción utilizados. El PIB mide todos los bienes y servicios producidos en el país, proveniente de sociedades nacionales o extranjeras con exclusión de los bienes y servicios
6\% del área total del planeta, pero proveen cerca de un $38 \%$ de la valoración monetaria global anual generada por la biodiversidad, con un promedio de US\$12 billones dólares/año en bienes (alimento y materiales) y servicios ecosistémicos (regulación de perturbaciones y ciclo de nutrientes) (Costanza et al. 1997). Dentro de la cosmovisión capitalista que permea la cultura de la sociedad global, los servicios ecosistémicos representan hoy una forma prevaleciente de valorar la biodiversidad. Sin embargo, también existen otras cosmovisiones complementarias que incluyen valores asociados con una "ética ambiental".

Desde la ética ambiental podemos enfatizar

generados en otros países. En cambio, el PNB mide toda la producción de las empresas nacionales independientemente del lugar del mundo donde la producción se lleva a cabo (Costanza et al. 2014). 
al menos dos miradas para conocer y valorar el fenómeno de la biodiversidad: i) los valores de la naturaleza, con su distinción entre valor instrumental e intrínseco de la biodiversidad (Rozzi, 1997); y ii) la concepción del ethos, con nuevas miradas desde la ética ambiental sudamericana que proponen recobrar la forma más arcaica de concebir la palabra ethos, que en su raíz etimológica significa "madriguera, la morada de un animal" (Rozzi et al. 2008). Esta definición de ethos vuelve a valorar el espacio físico vital (el hábitat) hacia el acto de habitar un hábitat para llegar al significado de la identidad de los seres vivos (co-habitantes). En consecuencia, esta cosmovisión ética arraigada en unidades ecosistémicas específicas de hábitatshábitos-habitantes, provee un fundamento conceptual para desarrollar estudios sobre la ética ambiental a través de colaboraciones transdiciplinarias (Rozzi et al. 2008).

La ética ambiental permite comprender y valorar con mayor profundidad las múltiples interacciones humanas con la biodiversidad costera, hecho de gran relevancia puesto que han constituido un punto focal para el asentamiento y alimentación del ser humano. Por ejemplo, más de la mitad de la población mundial habita dentro de los primeros $60 \mathrm{~km}$ de costa (Roberts \& Hawkins, 1999) y gran parte de su historia cultural ancestral y actual se ha visto beneficiada por la vida marina. Esta interacción también conlleva una historia de cambios ecológicos, como el colapso de las pesquerías y la extinción de especies, principalmente generados por la sobreexplotación y la degradación del hábitat (Lotze et al. 2006). Sin embargo, aún existen ecorregiones consideradas silvestres por atributos tales como baja densidad poblacional, escaso impacto ambiental histórico y alto porcentaje de áreas protegidas (Mittermeier et al. 2003). Uno de estos lugares se encuentra en el suroeste de Sudamérica, en la región de los canales y fiordos subantárticos de Magallanes ubicada en el sur austral de Chile ( $\left.42^{\circ} \mathrm{S}-56^{\circ} \mathrm{S}\right)$, entre el Golfo de Penas y el Cabo de Hornos.

Este trabajo propone integrar una perspectiva de la ética biocultural -con su distinción de unidades éticas-ecosistémicas (hábitat-hábitoshabitantes)- en la historia biológica y cultural del hábitat intermareal de la bahía Róbalo en la isla Navarino, Reserva de la Biosfera Cabo de Hornos.
Para ello, determinamos la riqueza y abundancia de los habitantes macroalgas y moluscos en el hábitat de la zona costera y caracterizamos sus hábitos de vida (abundancia estacional). Posteriormente, vinculamos esta información ecológica con los registros etno-ecológicos del pueblo yagán. De esta manera, identificamos sus interacciones bioculturales y las posibles valoraciones instrumentales e intrínsecas con el hábitat (intermareal), sus co-habitantes (moluscosalgas) y sus hábitos (estacionalidad). Este trabajo se realizó mediante la metodología de la Filosofía Ambiental de Campo (FILAC) (Rozzi et al. 2010), que propone nuevos puntos de referencia de observación, reflexión y prácticas de conservación biocultural desde el sur de Sudamérica.

\section{VISIÓN BIOCULTURAL DE LOS ECOSISTEMAS COSTEROS DE LA ECORREGIÓN SUBANTÁRTICA DE MAGALLANES}

La ecorregión subantártica de Magallanes alberga los bosques más australes del mundo, la cual no tiene réplica latitudinal en el Hemisferio Sur. Este bioma incluye hábitats de bosques terrestres (Rozzi et al. 2012), y su ámbito de distribución coincide con la ecorregión marina de fiordos y canales de Chile (Spalding et al. 2007). En el contexto de los hábitats costeros podemos enfatizar al menos tres atributos esenciales: i) la geomorfología de los canales y fiordos magallánicos se originó por la erosión glacial del continente debido al avance y retroceso de los hielos ocurridos durante el cuaternario (Silva \& Calvete, 2002). Además, durante el Último Máximo Glacial el territorio estuvo cubierto por hielo entre 23.000 y 19.000 años AP (Hulton et al. 2002); ii) la biota marina está compuesta por especies que estructuran la denominada unidad biogeográfica Magallánica (Camus, 2001). A su vez, hay taxones que aumentan su riqueza de especies en estas latitudes, entre ellos macroalgas y moluscos (Santelices \& Marquet, 1998; Valdovinos et al. 2003); iii) la región subantártica de Magallanes ha sido habitada por pueblos originarios que incluyen aónikenk, kawéskar, selk'nam, haush y la etnia más austral del planeta, el pueblo yagán o yámana, quienes han cultivado una estrecha relación con sus 
hábitats y desarrollado un refinado conocimiento ecológico (Rozzi, 2013).

Las macroalgas y moluscos están dentro de los ensambles de mayor riqueza de especies y abundancia en ambientes intermareales (Broitman et al. 2011), y la región de canales y fiordos magallánicos presenta gran heterogeneidad intermareal donde las macroalgas y moluscos conforman diversos biotipos (Soto et al. 2012). Solo en el hábitat intermareal se han registrado 56 especies de macroalgas (Cornejo, 1996) y 34 especies de moluscos (Benedetti-Cecchi \& Cinelli, 1997; Guzmán \& Ríos, 1981; Mutschke et al. 1998; Ojeda et al. 2014; Ríos \& Mutschke, 1999). La variabilidad en la abundancia de estos ensambles puede estar afectada por cambios estacionales debido a la intensidad de la radiación solar y al fotoperiodo (e.g., Gunnarsson \& Ingolfsson, 1995). Para las altas latitudes, tales como los canales magallánicos, se han documentado marcados cambios en fotoperiodo $e$ intensidad de radiación solar: durante el invierno (julio) el promedio es de 8 horas luz con una radiación solar de $29 \mathrm{Wm}^{-2}$, mientras que en el verano (enero) se registra un promedio de 14 horas luz con una radiación solar de $267 \mathrm{Wm}^{-2}$ (Butorovic, 2009). A pesar de las marcadas variaciones lumínicas, el impacto de estos cambios estacionales sobre la biodiversidad intermareal magallánica ha sido escasamente documentado.

Desde una visión antropológica, la estacionalidad se ha relacionado con el consumo de macroalgas. En el sitio arqueológico Monte Verde, uno de los asentamientos humanos más antiguos del Continente Americano con data de 14.600 años AP (Dillehay et al. 2008), se encontró que las macroalgas Gigartina sp., Porphyra sp., Macrocystis pyrifera, Durvillaea antarctica, Mazzaella sp. y Sarcothalia crispata tenían uso medicinal y como alimento directo (Dillehay et al. 2008). Se infiere que estos grupos humanos efectuaban su extracción principalmente entre principios de primavera y comienzos de otoño (Dillehay et al. 2008), probablemente en sincronía con sus ciclos estacionales.

La historia humana de los canales y fiordos de la ecorregión subantártica de Magallanes ha estado entretejida con el borde costero. Los pueblos originarios como los kawésqar y yagán tenían hábitos de vida canoeros y se alimentaban fundamentalmente de especies marinas (Orquera et al. 2012). Su dieta incluía mamíferos marinos (ballenas y lobos), aves marinas (cormoranes, albatros), y otras formas de vida, como moluscos y macroalgas (Emperaire, 1963; Orquera et al. 2012). La estrecha interacción con la biodiversidad del hábitat marino no solo se remitía al consumo como alimento directo, también incluía la caracterización del paisaje y el cultivo de hábitos más complejos de carácter estético y artístico (Emperaire, 1963). Por ejemplo, los kawésqar asignaban una división territorial asociada a la macroalga Durvillaea antarctica (cochayuyo) y denominaban "Málte" a lugares con presencia de esta macroalga y con gran intensidad de oleaje; por el contrario, "Jáutok" era una zona sin D. antarctica y con baja intensidad de oleaje (Aguilera \& Tonko, 2011). En el pasado, también los yagán desarrollaron sus hábitos de vida en el borde costero donde se alimentaban, construyeron sus viviendas y cultivaron su cosmovisión relacionada con la naturaleza austral (véase Gusinde, 1986). En la actualidad, los grupos humanos en la Provincia Antártica Chilena se ubican casi en su totalidad en el único centro urbano, Puerto Williams, representados por residentes permanentes, personal de la Armada de Chile y sus familias, pescadores residentes y esporádicos, empleados públicos, operadores de turismo, y pobladores descendientes del pueblo yagán (Molina, 2011).

En esta localidad austral las interacciones ligadas al mar son: i) pesca artesanal de la centolla (Lithodes santolla), centollón (Paralomis granulosa), erizo (Loxechinus albus) y luga roja (Gigartina skottsbergii); ii) resguardo de la soberanía y fiscalización marítima (Armada de Chile); iii) transporte para el abastecimiento de centros urbanos, y iv) navegaciones turísticas y de investigación. También se producen hábitos de carácter más artesanales por parte de los descendientes del pueblo yagán como tejidos de junco, confección de cabezas de arpón de hueso de ballena y de miniaturas de canoa con madera de coigüe de Magallanes (Nothofagus betuloides), y recolección en el intermareal de los gasterópodos lapa (Fissurella spp.) y maucho (Nacella spp.). Estas últimas prácticas de 
subsistencia son cada vez más escasas debido al incremento en la frecuencia de floraciones algales masivas o marea roja ${ }^{2}$.

\section{METODOLOGÍA DE LA FILOSOFÍA AMBIENTAL DE CAMPO (FILAC)}

Para reconectar una integración entre la historia biológica y cultural con el hábitat, y en particular con el entorno natural costero de los canales y fiordos subantárticos, es necesario introducir metodologías que permitan el despliegue de estos re-encuentros. La FILAC se basa en el marco conceptual de la ética biocultural e interrelaciona los hábitats (dónde vivimos), los hábitos (cómo vivimos) y los co-habitantes (quiénes somos) (Rozzi et al. 2008). La FILAC propone integrar diversos modos de observar y conocer el entorno natural, para así practicar una integración interdisciplinaria entre diversos dominios del conocimiento (ecológico, etnoecológico, histórico y filosófico), La amplitud de interacciones de la FILAC puede ser comprendida analizando cada uno de sus términos:

i) Filosofía: comprende una dimensión epistemológica porque los estudiantes e investigadores no solo investigan la diversidad biológica y cultural, sino también cómo se investiga esta diversidad (Rozzi, 2012). Incorpora perspectivas de ciencias, artes, humanidades, economías y conocimiento tradicional local. La filosofía nos traslada a la reflexión sobre la pregunta cómo conocemos, fundamento del fenómeno del conocer, y en particular del cómo conocer el entorno natural; por lo tanto, es posible incorporar una aproximación epistemológica en nuestra metodología. La filosofía comprende también una dimensión ética porque los estudiantes, investigadores, tomadores de decisiones y otros participantes no solo conducen investigaciones y aprenden sobre la diversidad biológica y cultural, sino también reflexionan sobre cómo cohabitar, ponen en práctica una ética que

2 El fenómeno de la Marea Roja afecta a invertebrados filtradores como los choritos (M. edulis platensis) y cholga (Aulacomya atra). Las causas provienen de la proliferación explosiva de microalgas nocivas para el ser humano (Guzmán et al. 2002). sustente la diversidad biocultural, y discuten políticas ambientales que contribuyan a la sustentabilidad de la vida.

ii) Ambiental: la palabra ambiente tiene una raíz etimológica en el verbo ambere (latín) que significa "rodear" o "estar a ambos lados". De esta forma, el término ambiental aborda lo que rodea a un ser vivo; por lo tanto, todo conocer y hacer se despliega en un hábitat o ambiente. Este adjetivo es añadido con el fin de superar la reducción prevaleciente de la ética moderna a los asuntos puramente humanos, haciendo explícito el significado antiguo de ética ${ }^{3}$ y la dimensión socio-ecológica de la ética descritos por las ciencias contemporáneas (Rozzi, 2012).

iii) Campo: los investigadores y estudiantes pueden percibir e investigar en terreno componentes y procesos de la diversidad biológica y cultural que quedan fuera del dominio experiencial de la educación formal. Al integrar en el campo los sentidos y las emociones junto con la racionalidad, se logra una percepción integral de los co-habitantes en sus hábitats locales y de esta forma, mediante esta experiencia, la diversidad biocultural deja de ser un mero concepto u objeto de estudio y comienza a ser una experiencia y conocimiento de co-habitar con diversos seres vivos e historias de vida (Rozzi, 2012). En la FILAC, la experiencia y el aprendizaje sobre una teoría de la naturaleza dentro del aula se traslada al terreno (incluyendo hábitats costeros, comunidades $\mathrm{y} / \mathrm{o}$ instituciones que los investigan $\mathrm{y} / \mathrm{o}$ administran), donde la naturaleza se transforma en una experiencia vivida y donde estudiantes, investigadores, políticos y público en general pueden desplegar emociones, observar y valorar la biodiversidad en su plenitud.

La aproximación metodológica de la FILAC comprende un ciclo de cuatro pasos: i) trabajo de investigación interdisciplinaria ecológica, etnoecológica y filosófica, ii) composición de

3 En su forma más arcaica, la palabra griega ethos significa madriguera, la morada de un animal. Por su extensión del uso de de la palabra, su significado llego a incluir las moradas de los seres humanos (Rozzi et al. 2010). 


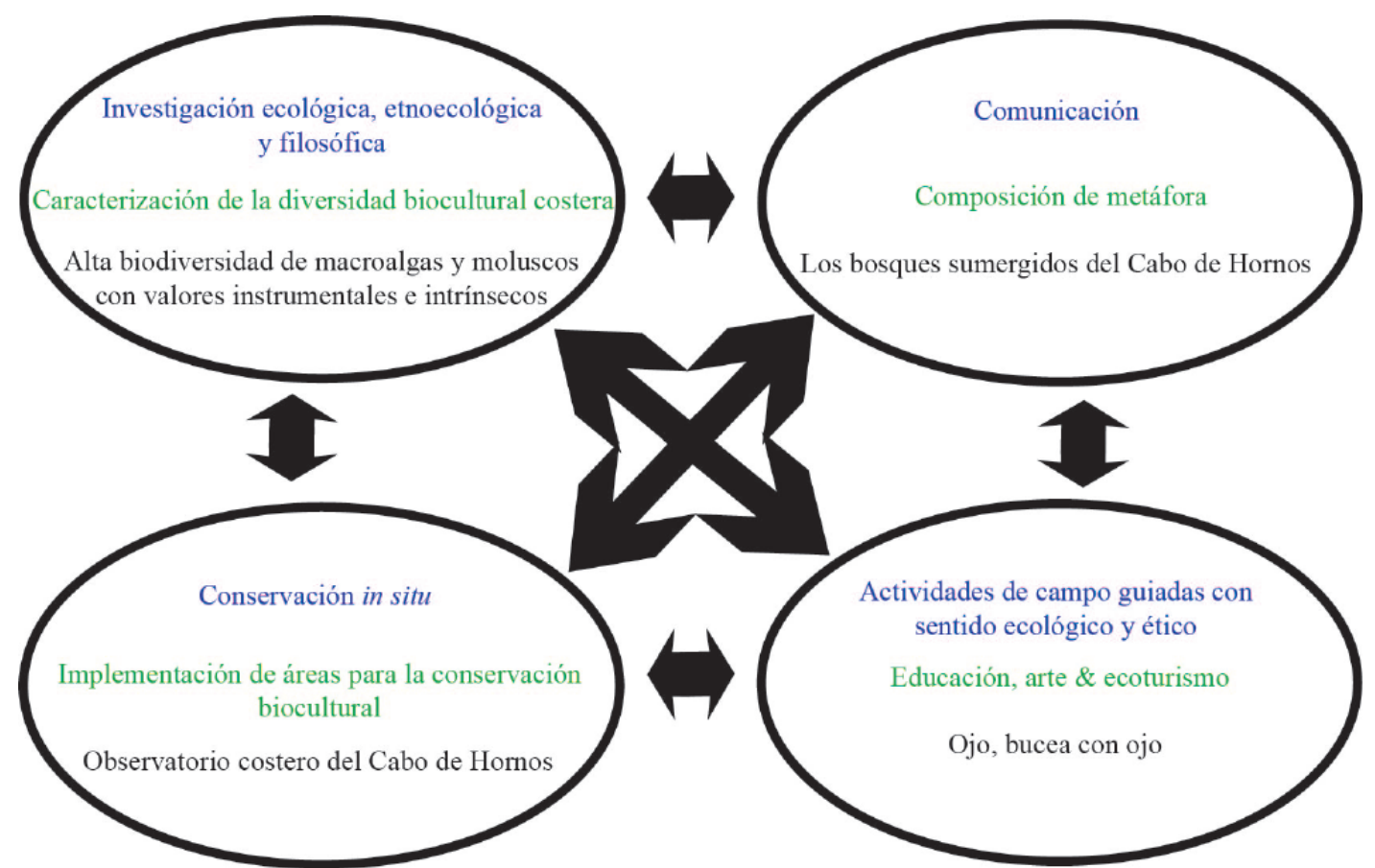

Fig. 1. Representación esquemática del ciclo de la Filosofía Ambiental de Campo (FILAC) para el desarrollo de este trabajo que investiga y procura contribuir a la conservación de la diversidad biológica y cultural de los hábitats costeros de la bahía Róbalo, canal Beagle, en la ecorregión subantártica de Magallanes. En color azul se indica el paso metodológico; en verde, el método utilizado y en negro, los resultados alcanzados.

metáforas y comunicación a través de relatos simples, iii) diseño de experiencias de campo guiadas con sentido ecológico y ético, y iv) definición e implementación de áreas de conservación in situ (ver Rozzi et al. 2010) (Fig. 1).

\section{Paso 1: investigación interdisciplinaria}

Investigación ecológica. La investigación ecológica sobre la composición y variabilidad estacional de macroalgas y moluscos ha sido publicada en gran parte (ver Ojeda et al. 2014; Ojeda et al. en revisión). Por esta razón, este trabajo se enfoca sobre la interacción de la composición y variabilidad estacional de macroalgas y moluscos, y su relación con los diversos hábitos de vida del pueblo yagán. El estudio se realizó durante los años 2008 y 2009 en la bahía Róbalo, canal

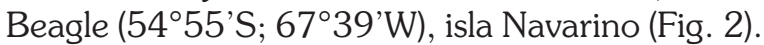
La bahía Róbalo posee una longitud aproximada de $6,5 \mathrm{~km}$ y tiene la influencia de agua dulce proveniente del río Róbalo. Se caracteriza por presentar diferentes grados de exposición al oleaje, con vientos predominantes del oeste (ver Santana et al. 2006). Desde una perspectiva horizontal, el intermareal presenta diferentes tipos de sustrato rocoso: guijarro, canto rodado pequeño, canto rodado grande y terraza. Por lo tanto, se definieron seis sectores, cada uno con una extensión aproximada de $150 \mathrm{~m}$ en paralelo a la línea de costa (Fig. 2).

La colecta de macroalgas y moluscos se realizó en cada uno de los seis sectores durante el otoño (mayo-2008), invierno (agosto-2008), primavera (octubre-2008) y verano (enero-2009), considerando tres niveles intermareales (ver protocolo Benedetti-Cecchi \& Cinelli, 1997). Con los valores y fechas de las mareas más altas y bajas para la localidad de Puerto Williams (SHOA, 2008) y trabajo de campo en la bahía Róbalo, se definieron niveles intermareales altos, medios y bajos y en cada uno de ellos se muestrearon al azar cuatro cuadrantes de 25 × $25 \mathrm{~cm}$. El diseño de muestreo fue de tipo anidado jerárquico: 4 (estaciones) x 6 (sectores) x 3 (niveles intermareales) x 4 cuadrantes $=288$ muestras. Las macroalgas y moluscos extraídos de 


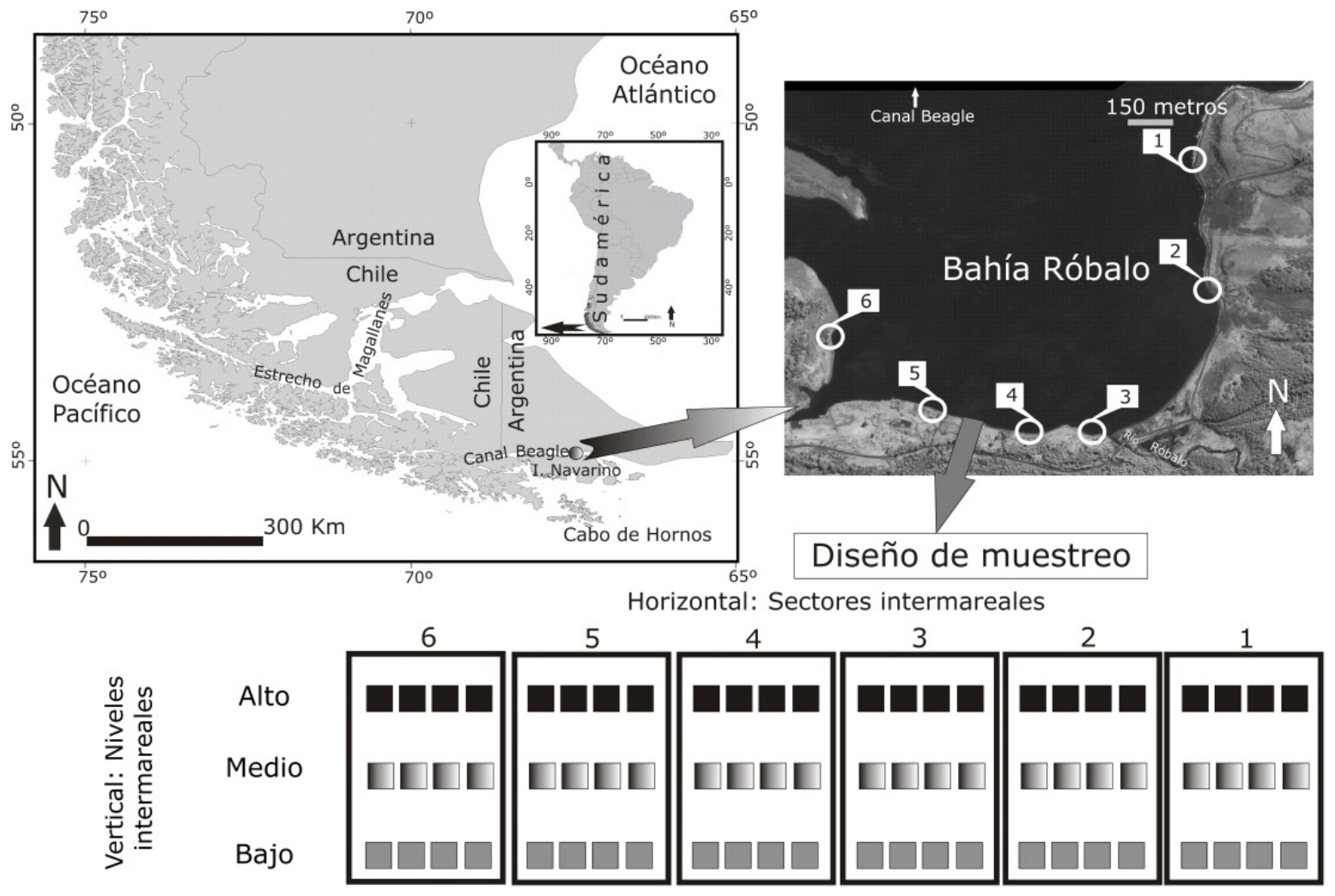

Fig. 2. Sitio de estudio en la bahía Róbalo, canal Beagle (5455’S; 67³9’O), isla Navarino, Reserva de la Biosfera Cabo de Hornos, Chile. A escala espacial horizontal se distinguieron seis sectores intermareales y a escala vertical se definieron tres alturas intermareales: alto, medio y bajo.

los cuadrantes se almacenaron en formalina al 5\% para su identificación a nivel de género o especie. Las macroalgas coralinas se excluyeron del análisis. La abundancia de macroalgas se estimó mediante la biomasa húmeda (g)/especie/cuadrante en $625 \mathrm{~cm}^{2}$, y la de moluscos se determinó por el número de individuos/especie/cuadrante en $625 \mathrm{~cm}^{2}$. Para evaluar los cambios estacionales de la biomasa del ensamble de macroalgas y moluscos se utilizó el análisis de varianza multivariado de permutaciones PERMANOVA (ver Anderson, 2005). Para testear los cambios específicos de las especies más conspicuas se utilizó el porcentaje de similitud (SIMPER) (Clarke, 1993).

Investigación filosófica y etnoecológica. En la ética ambiental anglosajona ha sido central la distinción entre valor intrínseco, asociado a un eco- o bio-centrismo, y valor instrumental, asociado a un antropocentrismo (Rozzi, 1997). Una justificación para el valor intrínseco de la biodiversidad se fundamenta en el parentesco evolutivo entre los seres humanos y el conjunto de los seres vivos, y una justificación central para el valor instrumental se fundamenta en las redes de interacciones entre los diversos seres vivos, incluidos los seres humanos; en consecuencia, el bienestar de nuestra especie depende del bienestar de la diversidad biológica (Rozzi, 1999). El valor intrínseco se refiere a la valoración de una entidad "en sí misma" (Sandler, 2012), que puede considerar diferentes niveles de organización (individuos, especies y ecosistemas) (Palmer, 2013). Según Ronald Sandler (2012), podemos distinguir dos tipos de valoración intrínseca: subjetiva y objetiva (Sandler, 2012). La valoración intrínseca subjetiva es generada por el observador humano. Callicott (1989) destaca que el ser humano valora algo en sí mismo, no solo porque algo pueda entregarle algún beneficio instrumental, sino tambien porque esta entidad genera una diversidad de valoraciones intrínsecas hacia el ser humano (e.g., momentos 
personales, artefactos culturales y religiosos, ceremonias y ritos, logros, y sitios históricos) y ellos lo hacen por una variedad de razones (e.g. por lo que representa una entidad, lo que encarna, su rareza, su historia, su belleza) (Sandler, 2012). En contraste, en la valoración intrínseca objetiva el valor reside en los entes, independientemente del observador humano y sus juicios. Esto funda una visión de historia natural asociada al valor en sí mismo de una especie por su herencia evolutiva (Sandler, 2012). Dentro de la valoración objetiva también se ha propuesto el valor inherente, que sostiene que las entidades no-humanas poseen un bien propio e intereses que las personas deberían cuidar (Sandler, 2012).

Nuestro trabajo explora diversos tipos de valores y prácticas de cohabitación entre el pueblo yagán y la biodiversidad costera desde la óptica de: (a) la ética ambiental contemporánea, en particular su distinción de valoración instrumental e intrínseca de la biodiversidad, y (b) la ética biocultural considerando los conceptos de hábitat del borde costero, habitantes algas-moluscos y hábitos, especialmente de estacionalidad. Para ello se realizó una revisión bibliográfica etnoecológica que practicaba el pueblo yagán o yamana. ${ }^{4} \mathrm{La}$ identificación de valores asociados a macroalgas y moluscos costeros se basó en tres fuentes descritas a continuación.

i) Análisis de textos fundamentales de la antropología yagán:

- Louis-Ferdinand Martial, Paul Hyades y Joseph Deniker. Edición científica de Dominique Legoupil y Alfredo Prieto (2007) en el libro Etnografía de los Indios Yaghan en la Misión Científica del Cabo de Hornos 1882-1883. Esta edición fue dividida en dos partes, la primera corresponde a la historia de viaje del capitán Louis Martial (tomo I de la tabla de materias de la versión original), y la

4 De acuerdo a Orquera et al. (2012), en el siglo XIX los indígenas canoeros que vivían en el sur de Tierra del Fuego decían ser yámana (o sea "humano", no animal) y llamaban a su lenguaje yaman'hahsha ("voz humana"). Es decir, su idioma era expresión de autoconciencia grupal frente a todos quienes -otros indígenas o extranjeros- hablaban otro idioma. Por lo tanto, se debe respetar el nombre yámana respecto de la época en que se produjeron los primeros contactos con los europeos. Sin embargo, cuando los misioneros segunda parte corresponde a la antropología y etnografía realizada por Paul Hyades y Joseph Deniker (tomo VII de la tabla de materias de la versión original).

- Martín Gusinde (1986) en el libro Los Indios de Tierra del Fuego. Tomo II: Los Yámanas. Traducción de Herbert Wolfgang Jung, Carlota Romero y Beatriz Romero, bajo la dirección del Dr. Werner Hoffmann.

- Martín Gusinde (1951) libro Hombres Primitivos en la Tierra del Fuego: De investigador a compañero de tribu, obra traducida por Diego Bermúdez Camacho.

- Wilhelm Koppers (1997) en el libro Entre los Fueguinos en su primera edición al español traducida por Carlos Brinkmann.

- Lucas Bridges (1952) libro El Último Confín de la Tierra edición traducida por Elena Cruz de Schwelm.

- Charles Darwin (1939) Voyages of the Adventure and Beagle. Vol III, London, Henry Colburn, Great Marlborough Street.

- Dánae Fiore \& María Lydia Varela (2009) libro Memorias de Papel: Una Arqueología Visual de las Fotografías de Pueblos Originarios Fueginos.

ii) Revisión de las publicaciones arqueológicas realizadas en la región del Cabo de Hornos y Canal Beagle.

Literatura científica arqueológica principalmente en los trabajos realizados Legoupil (1993), Lefèvre (1993), Orquera (2000), Orquera y Piana (1991), Orquera y Piana (2002) y Orquera et al. (2012).

iii) Durante dos años participamos en ocho actividades culturales con la artesana yagán Julia González Calderón. Estas actividades duraron entre 3 a 6 horas y se llevaron a cabo en la costa de la isla Navarino. Utilizando

anglicanos se aproximaron al área, establecieron relación primeramente con los habitantes del estrecho que separa las islas hoy llamadas Navarino y Hoste (canal Murray); ese canal se llamaba Yahgashaga y una de sus playas Yahga. Esos primeros misioneros aún no dominaban el idioma autóctono y desconocían la significación de yámana, por lo que de esos nombres derivaron en el apelativo "yaghan" en idioma inglés o finalmente en su castellanización "yagán" (Orquera et al. 2012). 
participación observante se registró el profundo conocimiento tradicional ecológico que Julia González tiene de la biodiversidad costera. ${ }^{5}$

Con base en las experiencias analizadas y observadas dentro de estas tres fuentes de comunicación, se identificaron diversas valoraciones y percepciones asociadas a las macroalgas $y$ moluscos costeros de la Comuna de Cabo de Hornos. Con esta investigación interdisciplinaria fue posible enriquecer y nutrir los pasos siguientes de la metodología FILAC (i.e., ii-Comunicación; iii-Actividades de campo guiadas con sentido ético y iv- Conservación in situ), con el objetivo de enfatizar y valorar nuestra historia ancestral ambiental subantártica.

\section{Paso 2: Comunicación}

Visiones positivistas de la ciencia que han prevalecido durante la segunda mitad del siglo XX han sostenido que las metáforas no pueden formar parte del discurso científico (Rozzi et al. 2010), puesto que se consideran como figuras retóricas y ambiguas (Díaz, 2006). Sin embargo, recientemente se ha propuesto que las metáforas constituyen figuras cognitivo-lingüísticas que forman parte de nuestros esquemas conceptuales y generan un agudo carácter esclarecedor de lo abstracto, tanto en los ámbitos de pensamiento cotidiano como científico (Díaz, 2006). Esto es reafirmado por el investigador de lingüística cognitiva George Lakoff, quien propone que la metáfora no es un fenómeno puro y superficialmente lingüístico sino que forma parte de la estructura cognitiva del ser humano, y que gran parte de nuestros esquemas conceptuales son metafóricos; comienzan a representarse en un objeto bajo la forma de otro objeto con el que tenemos una experiencia más cercana (Díaz, 2006). Es decir, se incluye un pensamiento analógico para lo que se procura investigar y comunicar. Por lo tanto, la metáfora se transforma en una necesidad básica del científico que pretende introducir un término más concreto, más físico, más gráfico para poder

5 Regreso a la Madriguera (Sepúlveda, 2011), documental realizado en el Parque Etnobotánico Omora, dirigido por Jaime Sepúlveda, producido por el Programa de Conservación Biocultural Subantártica (Universidad arribar a su comprensión (Díaz, 2006). Por estas razones, nuestro estudio incorpora la composición de metáforas con un doble propósito:

(a) generar una figura comunicativa para el público en general que visualice analógicamente la diversidad y los cambios de las macroalgas y moluscos del borde costero de la zona de la bahía Róbalo, y

(b) vincular los descubrimientos de la investigación ecológica, etnoecológica y filosófica a través de un pensamiento analógico que integra hechos, valores $y$ acciones en prácticas de educación, ecoturismo y conservación biocultural.

\section{Paso 3: Actividades de campo}

guiadas con sentido ético y ecológico

El año 2007 por primera vez en la historia de la especie humana más del $50 \%$ de la población habita en zonas urbanas que en áreas rurales (Rozzi, 2012). Es decir, hemos pasado desde un entorno natural silvestre inmerso en la biosfera hacia un entorno urbano y tecnológico inmerso en la tecnósfera. Esto ha generado cambios radicales, no sólo en las actividades físicas y emocionales sino también en los imaginarios cognitivos y del lenguaje para comprender y valorar la biodiversidad. Las ciudades aíslan física y cognitivamente a los habitantes urbanos de la biodiversidad nativa que aún habita en los hábitats periurbanos, rurales y remotos (Rozzi, 2012). En el contexto de la educación ambiental chilena, el neurobiólogo y pensador Humberto Maturana escribe en el prólogo del libro "La Enseñanza de la Ecología en el Entorno Cotidiano" que:

Los seres humanos pertenecemos a una historia cultural que nos separa cada vez más del mundo natural. En la actualidad crecemos sin conocer los nombres de las plantas autóctonas o de los animales silvestres que aún pueden verse en nuestro entorno, a menos que los estudiemos

de Magallanes, Instituto de Ecología y Biodiversidad y Universidad de North Texas): httm://vimeo. com/31905600 
especialmente. Ya no aprendemos como algo natural, lo natural de nuestra pertenencia a la biósfera e interdependencia vital con todos los otros seres vivos que la constituyen y con los componentes no vivos de la corteza terrestre...6

Para superar este distanciamiento del conocer el entorno natural marino, es fundamental diseñar y proponer actividades que permitan recobrar el observar, para religar el lenguaje ecológico principalmente en áreas como la educación. Nuestro trabajo procura generar hábitos de "encuentros directos" con la diversidad biológica costera. Las actividades de campo han sido diseñadas con múltiples actores (que incluyen a artesanos de la Comunidad Indígena Yagán, profesores de educación ambiental, buzos, y los propios estudiantes del Liceo Municipal Donald Mclntyre Griffith de Puerto Williams), y talleres de educación ambiental en jardines infantiles y liceos en Puerto Williams y Punta Arenas (Contador et al. 2015; Ojeda et al. 2013).

\section{Paso 4: Conservación in situ}

Nuestro estudio se realizó en la Reserva de la Biosfera Cabo de Hornos, que tiene una extensión de 4.884.274 ha que por primera vez en Chile integró ecosistemas marinos y terrestres (Rozzi et al. 2007). Las reservas de la biosfera procuran superar la perspectiva preservacionista que excluye a los humanos de las áreas protegidas. En contraste, el Programa del Hombre y la Biosfera de la UNESCO (Programa MaB) coordina las reservas de la biosfera que intentan reconciliar la conservación de la biodiversidad con las necesidades sociales, culturales, recreativas y ecológicas asociadas a los seres humanos (Guevara \& Laborde, 2008).

En concordancia con el enfoque del Programa $\mathrm{MaB}$, el cuarto paso de la FILAC procura la habilitación de espacios físicos para la conservación in situ con cuatro objetivos principales: i) preservar la diversidad de especies, ii) proteger los hábitats e interacciones ecológicas, iii) posibilitar la interacción de la comunidad local y los visitantes para observar y disfrutar in

6 Prólogo de Humberto Maturana en Rozzi et al. (1997, p. 9). La Enseñanza de la Ecología en el Entorno Cotidiano. situ las interacciones ecológicas entre los cohabitantes, accediendo a una experiencia vívida con la diversidad biocultural subantártica, y iv) estimular un sentido de responsabilidad y empatía en los estudiantes y otros participantes, puesto que la biodiversidad no es considerada solo como un objeto de estudio sino como una comunidad de sujetos o seres vivos; es decir, los co-habitantes deben ser conocidos y conservados junto con sus hábitats. Nuestro estudio propone definir un hábitat de conservación de la diversidad de macroalgas y moluscos en la bahía Róbalo habilitando elementos interpretativos para que los visitantes (e.g., turistas, profesores, estudiantes) puedan reconocer, valorar y conservar la biodiversidad costera.

\section{RESULTADOS Y CONCLUSIÓN}

\section{Paso 1. Investigación ecológica, etnoecológica y} filosófica

Composición de especies de macroalgas y moluscos. El ensamble de macroalgas durante el período anual alcanzó 49 taxa diferentes; se identificaron 20 a nivel de género y 29 a nivel de especie, todas ellas pertenecientes a 27 familias. Las especies con mayor porcentaje de contribución en biomasa anual fueron: Ceramium virgatum (16\%), Ulva intestinalis (9\%), Ectocarpus siliculosus (8\%), Ulva sp. (7\%), Adenocystis utricularis (6\%) y Pyropia columbina (4\%). Para el ensamble de moluscos se determinaron 34 especies pertenecientes a 22 familias. Dos especies presentaron la mayor abundancia relativa anual, los bivalvos sésiles Mytilus edulis chilensis (46,6\%) y Perumytilus purpuratus (43,81\%) (Ojeda et al. 2014). Al considerar solo las especies móviles, destacó la abundancia relativa de dos gastrópodos herbívoros, Laevilitorina caliginosa $(42,9 \%)$ y Siphonaria lessonii (21,8\%), y los Patelogastrópodos (Nacella deaurata, Nacella magellanica y Nacella flammea, 12,7\%) (Ojeda et al. 2014).

Estructura estacional. Las variaciones estacionales del fotoperiodo y Radiación Fotosintéticamente Activa (Luz PAR) en el 2010

Módulo de Ciencia Naturales. Ministerio de Educación de Chile, Santiago, Chile. 
fueron notables. En invierno (junio) se registraron 8 horas de luz con 23,2 $\mathrm{Wm}^{-2}$ luz PAR y en verano (diciembre) 14 horas luz con $164,7 \mathrm{Wm}^{-2}$ luz PAR (CEAZA-MET, 2010). La temperatura del aire a 1 metro sobre el suelo tuvo una mínima de $-6,7^{\circ} \mathrm{C}$ (junio) y una máxima de $27,2^{\circ} \mathrm{C}$ (enero) (CEAZA-MET, 2010). La temperatura superficial del mar tuvo valores mínimos de $4,7^{\circ} \mathrm{C}$ (invierno) y máximos de $10,9^{\circ} \mathrm{C}$ (verano) en la Bahía Róbalo.

Las comunidades costeras de macroalgas de la bahía Róbalo tuvieron un aumento de ca. $300 \%$ en biomasa húmeda durante el verano en comparación con el invierno (Permanova: $\mathrm{P}<0,05)$. La biomasa promedio por cuadrante fue de $21,3 \pm 5,2 \mathrm{~g} / 625 \mathrm{~cm}^{2}$ en invierno y de 69,5 \pm $8,6 \mathrm{~g} / 625 \mathrm{~cm}^{2}$ en verano (Fig. 3, Ojeda et al. en revisión). El número de especies también aumenta en verano (Fig. 3), puesto que algunas macroalgas como Nothogenia fastigiata y Ceramium virgatum son perennes o anuales, mientras que otras como Adenoscystis utricularis, Ulva spp. y Pyropia columbina son de tipo estacional y presentan un crecimiento significativo durante el verano. Pyropia columbina (luche) crece en el intermareal superior de la bahía Róbalo, es comestible y tradicionalmente recolectada por pescadores artesanales en la Región de Magallanes. En la zona submareal también se registra una gran variabilidad estacional de macroalgas. En bosques de Macrocystis pyrifera en la bahía Tekenika (isla Hoste) la biomasa húmeda varía desde $26.400 \pm$ $4.400 \mathrm{~g} / \mathrm{m}^{2}$ en invierno hasta $53.700 \pm 12.300$ $\mathrm{g} / \mathrm{m}^{2}$ en verano (Mansilla et al. 2009). En Puerto Toro (isla Navarino) se ha registrado que la biomasa del sotobosque de bosques de macroalgas pardas aumenta desde el invierno $\left(180 \mathrm{~g} / \mathrm{m}^{2}\right)$ al verano $\left(350 \mathrm{~g} / \mathrm{m}^{2}\right)$ (Santelices \& Ojeda, 1984). Por lo tanto, la variabilidad estacional de macroalgas entre invierno y verano no ocurre solo en la Bahía Róbalo sino que en otros sitios en la Reserva de la Biosfera Cabo de Hornos.

Los moluscos también presentaron una variación estacional significativa en la bahía Róbalo, especialmente el ensamble de moluscos herbivoros (Permanova: $\mathrm{P}<0,05)$ (ver Ojeda et al. 2014). Para los macroherbívoros Patelogastrópodos del género Nacella (e.g., N. deaurata, N. magellanica y $N$. flammea) la abundancia promedio fue de sólo $0,13 \pm 0,06$ individuos $/ 625 \mathrm{~cm}^{2}$ en mayo, $y$ fue 15 veces mayor con $1,8 \pm 0,4$ individuos $/ 625 \mathrm{~cm}^{2}$ en enero (Fig. 4).

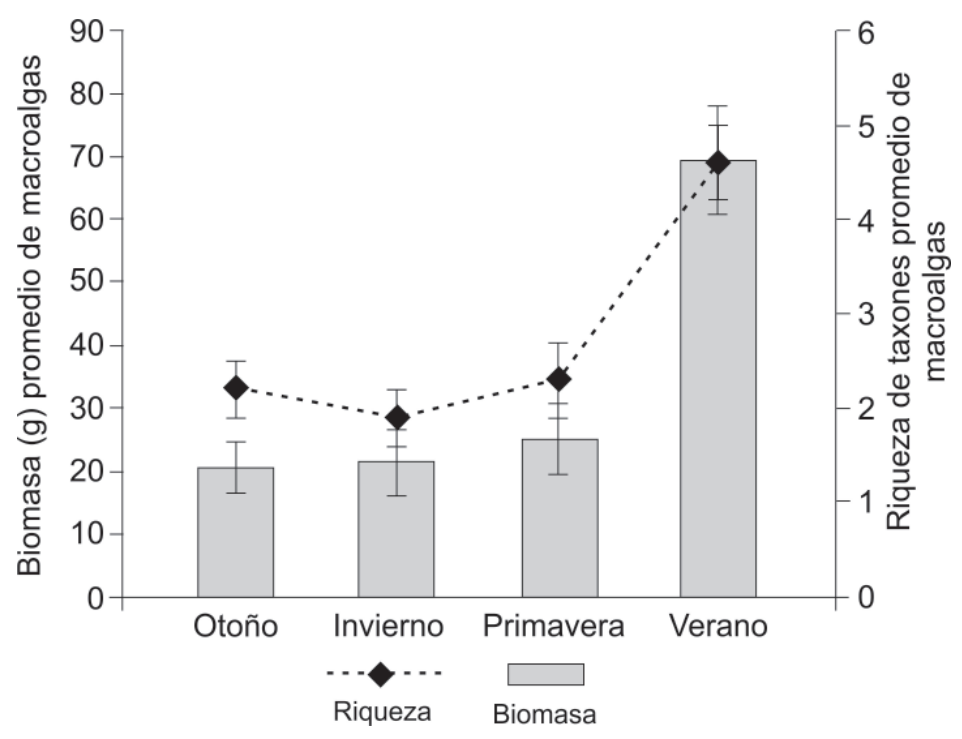

Fig. 3. Abundancia y riqueza de especies del ensamble estacional de macroalgas de la bahía Róbalo. Las barras grises muestran el promedio de biomasa del ensamble de macroalgas por cuadrante \pm E.E (error estándar). La línea negra indica el promedio estacional de la riqueza especies por cuadrante \pm E.E. La dimensión de cada cuadrante fue de $625 \mathrm{~cm}^{2}$, para cada estación se realizaron $\mathrm{N}=72$. (Figura modificada desde Ojeda et al. en revisión). 


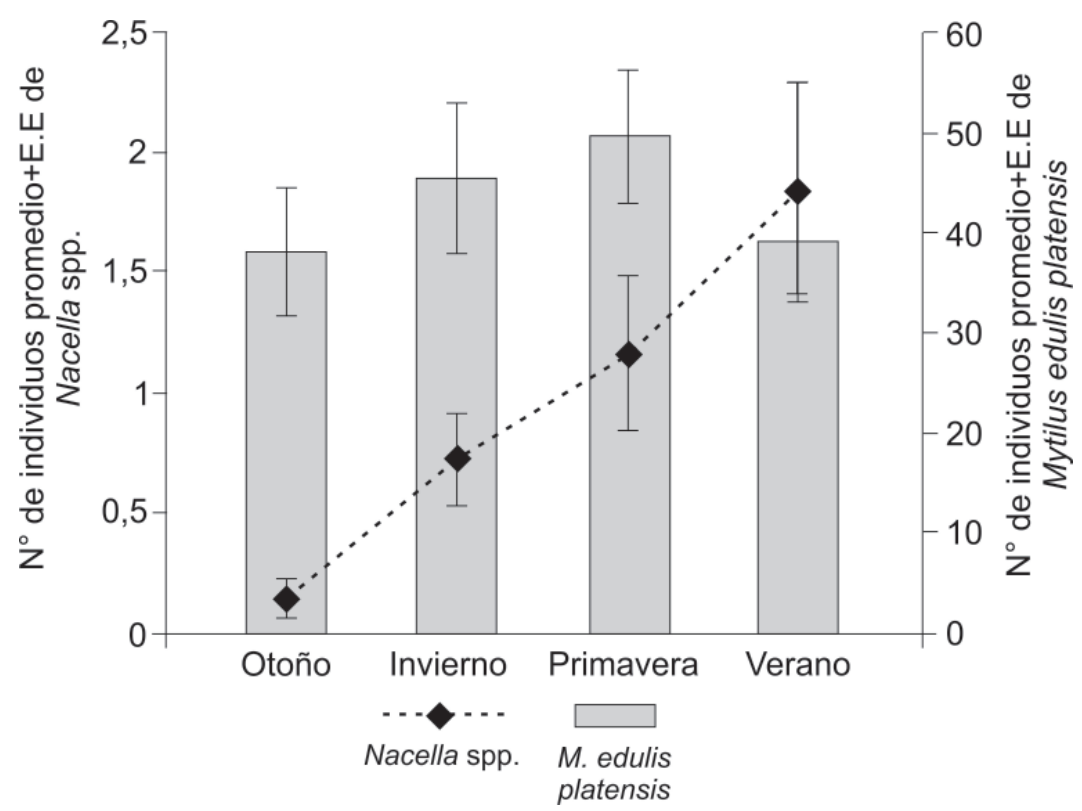

Fig. 4. Abundancia promedio \pm Error Estándar (E.E) del número de individuos pertenecientes al género Nacella (triángulos grises unidos por línea). Las barras indican la abundancia promedio \pm E.E del número de individuos de Mytilus edulis platensis. Muestreo realizado en el intermareal de bahía Róbalo; N=72 cuadrantes por mes, cada cuadrante tuvo una dimensión de $625 \mathrm{~cm}^{2}$.

El molusco más abundante de la bahía Róbalo, el chorito o mejillón Mytilus edulis platensis, no presentó una variación estacional en el número de individuos (Permanova: $\mathrm{P}>0,05$ ). Su abundancia promedio fue de $45,3 \pm 7,6$ individuos $/ 625$ $\mathrm{cm}^{2}$ en agosto y de $38,8 \pm 5,8$ individuos $/ 625$ $\mathrm{cm}^{2}$ en enero (Fig. 4). Para las matrices de $M$. edulis platensis, estudios previos en la zona del Estrecho de Magallanes ya habían documentado baja estacionalidad para la abundancia (Langley et al. 1980). Es relevante que el chorito púrpura, Perumytilus purpuratus, tampoco presentó variaciones estacionales significativas en su abundancia en la Bahía Róbalo (Ojeda et al. 2014).

Antecedentes etnoecológicos. Macroalgas. Las poblaciones canoeras han habitado en la isla Navarino y la región archipelágica del Cabo de Hornos desde hace más de 6000 años (Legoupil, 1993). La comunidad de vida marina incluyendo macroalgas, moluscos, peces, aves y mamíferos ha tenido un papel fundamental en la subsistencia de la vida humana (Orquera \& Piana, 2002). Las macroalgas proveen una base trófica y ecosistémica para los ambientes subantárticos costeros; por lo tanto, poseen un valor instrumental para la comunidad de seres vivos (humanos y otros-quehumanos). El valor de las macroalgas ha sido enfatizado por diversas expediciones científicas en canales australes desde el siglo XIX. Charles Darwin escribió en 1832:

Hay uno que por su importancia merece ser descrito de un modo especial: el alga gigante denominada Macrocystis pyrifera, crece en todas las rocas desde la línea de bajamar hasta una gran profundidad, tanto en la costa libre como en la de los canales... Por mi parte, solo puedo comparar estas grandes selvas acuáticas del hemisferio meridional a las terrestres de las regiones intertropicales... El número de seres vivos, de todos órdenes, cuya existencia depende intimamente del Macrocystis es maravilloso ...Cualquier cataclismo que destruyera la vegetación forestal de cualquier país, no creo que perecieran tantas especies de animales como con la destrucción de esta alga. Entre las hojas de esta planta viven numerosas especies de peces que en ninguna otra parte podrian 
hallar alimento y abrigo; con su destrucción morirían de inanición los muchos cuervos marinos y otras aves pescadoras; las nutrias, focas y marsopas perecerían también; y en el último término el salvaje fueguino (Darwin, 1939, p. 297).

No se conocen en profundidad las interacciones ecológicas de $M$. pyrifera (o huiro) con el habitar humano actual en ambientes subantárticos, pero existen antecedentes sobre su importancia ecológica para especies de alto valor económico y gastronómico. Por ejemplo, hay evidencia de grandes agrupaciones de juveniles de centolla (Lithodes santolla) asociadas a grampones de M. pyrifera (Cárdenas et al. 2007), lo mismo respecto a interacciones tróficas con el erizo de mar (Loxechinus albus) puesto que es probable que la principal fuente de alimento para este herbivoro sea M. pyrifera (Dayton, 1985), y existen registros sobre la importancia de esta macroalga como reservorio de masas de huevos de calamares pertenecientes a la especie Doryteuthis (Amerigo) gahi, un cefalópodo que adhiere sus masas de huevos a los estipes de $M$. pyrifera durante los meses de otoño e invierno (Rosenfeld et al. 2014).

El huiro, o aush en lengua yagán, tuvo un valor instrumental crucial para la subsistencia de este pueblo en la región austral. Martin Gusinde (1986: $529)^{7}$ describe que el estipe de $M$. pyrifera era utilizado como línea de pesca por sus propiedades de resistencia, elasticidad y fácil enrollamiento. $\mathrm{Al}$ estipe se le incorporaba una piedra pequeña como plomada a la que se amarraba el raquis de pluma de ave de $10 \mathrm{~cm}$ de largo y $4 \mathrm{~cm}$ de ancho con un nudo corredizo donde se insertaba el cebo (restos de chorito, carne de lobo marino o aves). La pesca se realizaba exclusivamente por mujeres durante todo el año extrayendo peces como Nothotenia tessellata, N. cornucola, Merluccius australis, Genypterus chilensis, entre otros.

Otro hábito común del pueblo yagán era el uso de $M$. pyrifera para anclaje de canoas. Lucas Bridges (1952, p. 57) menciona que una familia se dividía las tareas al arribar a la playa,

7 Martín Gusinde al realizar esta descripción del uso de herramienta de pesca de $M$. pyrifera, utiliza como referencia la experiencia descrita por el etnógrafo Paul Hyades en la exploración científica del Cabo de Hornos, realizada por el hombre bajaba a preparar el fuego y la mujer remaba algunas brazas hacia el "bosque de algas" (o palan $^{8}$ ) donde amarraba la canoa que quedaba firmemente atada. Martín Gusinde describe así la pesca del erizo:

Para recogerlos, la mujer se aleja un poco de la orilla, amarra la canoa a la maraña de algas de Macrocystis flotantes y busca a través del agua clara y serena los erizos de mar que puedan encontrarse adheridos en el fondo. (Gusinde, 1986, p. 526).

Gusinde (1951, p. 202) describe también la utilización del huiro para el varamiento de canoas en un terreno arenoso: las mujeres extraían un manojo del alga y lo extendían en el suelo arenoso porque su viscosidad facilitaba el deslizamiento de la madera. También las macroalgas se utilizaban para rellenar grietas de las canoas: se van tapando con musgos y algas, las pequeñas grietas de la madera, agujeros y aberturas de las paredes de la canoa (Gusinde, 1951, p. 198). Además, los bosques de huiro facilitaban la caza del lobo marino:

Cuando descubre, flotando cerca, grandes ovillos de alga Macrocystis recurre al arpón pequeño; allí irá a refugiarse la foca herida. Esto se debe a que, al sentir la punta de hueso dentada en el cuerpo, se esforzará en su dolor por sacudírsela de encima.... la foca invadida por el pánico se introduce en el bosque y se abre paso dificultosamente, pero lo único que logra es que la punta de hueso se desprenda de la muesca del asta....La foca y el arpón están intrincadamente enredados en el ovillo de algas y hacen imposible la huida.... Este método de caza es el que se utiliza con mayor frecuencia. Pero todo hombre debe contar con la presencia de los tan abundantes ovillos de algas flotantes en el lugar en que ha arrojado su pequeño arpón contra la foca (Gusinde, 1986, p. 498).

La literatura arqueológica y etnográfica del pueblo yagán no menciona el consumo directo de algas como alimento. Paul Hyades y Joseph

científicos franceses entre 1882-1883.

8 Los yamana nombran "palan" a un grupo grande y compacto de $M$. pyrifera separada de la costa por aguas profundas. Lucas Bridges (op. cit., pp. 58). 
Deniker (2007) señalan en su estudio etnográfico de la Misión Científica del Cabo de Hornos (18821883) que la flora marina no proporciona absolutamente nada a la alimentación de los fueguinos (Martial et al. 2007, p. 86). Parece extraño que los etnógrafos de los siglos XIX y $\mathrm{XX}$ no hayan registrado este hábito alimenticio, puesto que existen registros de consumo de algas como luche (Pyropia columbina) y cochayuyo (Durvillaea antarctica) por el pueblo kawesqar, cultura canoera geográficamente contigua a la yagán por el norte (Fiore \& Varela, 2009). En la actualidad, las macroalgas forman parte de la alimentación de algunos miembros de la comunidad yagán; la artesana Julia González recolecta luche para consumo durante la temporada de primaveraverano en la costa de las bahías Róbalo y Mejillones en la isla Navarino.

Antecedentes etnoecológicos. Moluscos. En las costas subantárticas del Cabo de Hornos los moluscos incluyen una variedad de grupos tróficos: herbívoros filtradores (Mytilus edulis chilensis), herbívoros móviles (Nacella deaurata), carnivoros móviles (Trophon geversianus) y carroñeros (Pareuthria fuscata) (Ojeda et al. 2014). Estos hábitos tróficos son fundamentales para entender la ecología costera de las zonas subantárticas, y también para entender la historia del poblamiento humano en la región austral. Podemos identificar un valor instrumental en los registros de diversas disciplinas como arqueología, historia y etnografía.

Uno de los usos más documentados es el alimenticio. Gusinde (1986, p. 471) destaca su importancia como alimento señalando que: los moluscos son para los aborígenes fueguinos lo que el pan es para el europeo. Según los registros de la arqueóloga Dominique Legoupil (1993) en la isla Navarino, los moluscos constituían el principal ítem alimenticio que incluían mayoritariamente a los bivalvos $M$. edulis chilensis (chorito) y Aulacomya atra (cholga), en menor abundancia los gasterópodos Nacella spp. (maucho) y Fissurella spp. (lapa), y con menor frecuencia Polyplacophoros (chitones), caracoles carnivoros $T$. geversianus y Acanthina monodon, y de manera muy excepcional el chorito pequeño púrpura Perumytilus purpuratus. En sitios arqueológicos de la costa norte del canal Beagle en Tierra del Fuego, M. edulis chilensis es el molusco más abundante; su longitud promedio varía entre $39,8 \pm 7,2 \mathrm{~mm}$ (Sitio Túnel IV) y 49,8 $\pm 10,2 \mathrm{~mm}$ (Sitio Shamakush X) (Orquera, 2000). En la actualidad, en las costas cercanas a los sitios arqueológicos, las longitudes promedio de estos choritos alcanzan 57,4 7,2 mm (Orquera, 2000). En las poblaciones de M. edulis chilensis de la bahía Róbalo en la isla Navarino registramos longitudes que alcanzan hasta $70 \mathrm{~mm}$ (Jaime Ojeda, comunicación personal), lo que podría estar asociado con la ausencia de recolección humana.

Es importante analizar el aporte nutricional del chorito. Considerando la longitud promedio registrada en los sitios arqueológicos, se puede estimar que 100 gramos de carne deshidratada contienen $65,8 \mathrm{~g}$ de proteínas y $350 \mathrm{kcal}$, aporte que según Orquera (2000) sería continuo durante el año puesto que existe una mínima variación estacional en su abundancia (véase más arriba). Estos moluscos proporcionan proteínas con alto contenido de sodio, calcio y fósforo, pero bajo contenido de lípidos, hidratos de carbono y hierro (Orquera, 2000). En la dieta del pueblo yagán los pinnípedos (específicamente el lobo de mar, abundante durante todo el año,) cuya carne, grasa y aceite eran fundamentales para contrarrestar las exigencias del frío y clima ventoso (Orquera et al. 2012). El consumo de huevos y carne de aves marinas en el archipiélago Cabo de Hornos, como fardelas y cormoranes, ocurría principalmente en primavera y verano (Lefèvre, 1993).

Los moluscos constituían un factor determinante para la elección de los sitios de asentamiento y construcción de chozas (Orquera, 2000). Los choritos fueron un alimento esencial para adaptarse a la vida nómade litoral, no tanto por su poder alimenticio sino por constituir un factor reductor de riesgos que neutralizaba situaciones de tensión en el aprovisionamiento de otros recursos de mejor calidad nutricional (Orquera, 2000). Por lo tanto, esta disponibilidad espacial y temporal era fundamental para el bienestar alimenticio durante el año. Respecto a la economía de los indígenas del archipiélago del Cabo de Hornos y la costa sur de la isla Navarino, Legoupil (1993, p. 119) señala que la factibilidad de la recolección de mariscos durante todo el año, representaba un factor de estabilidad 
importante para los nómades marinos que frecuentaban los archipiélagos de Patagonia y Tierra del Fuego.

Los moluscos también formaban parte de rituales de entrenamiento para chamanes, puesto que los aprendices no debían comer grasas ni aceites $y$, por lo tanto, su dieta estaba restringida a unos pocos choritos (Koppers, 1997, p. 151). Otro valor instrumental de los moluscos se refería al ornamental. Se confeccionaban collares de Fissurella aprovechando el orificio del ápice (Orquera \& Piana, 2002), mientras que Paul Hyades y Joseph Deniker (2007) describen que el adorno más frecuente era el collar de Margarella violacea (Martial et al. 2007, p. 94). La fabricación de pinturas para el cuerpo constituye otro elemento estético provisto por los moluscos y, según Gusinde,

La materia colorante blanca (tumarapu) es cal. Se aprecia particularmente la tierra caliza, pura y fina, que se encuentra en Puerto Róbalo y Puerto Eugenia... Las cantidades más pequeñas para necesidades de urgencia se obtienen recociendo algunas valvas de almejas en el fuego de la choza y triturándolas luego entre las piedras hasta pulverizarlas (Gusinde, 1986, p. 412).

Otro uso central de los moluscos se relaciona con la elaboración de herramientas. El raspador o ufker, que Todo adulto posee como mínimo uno de su propiedad personal; le es más imprescindible que el cortaplumas al europeo (Gusinde, 1986, p. 475), estaba compuesto de tres partes: una valva de chorito de al menos $10 \mathrm{~cm}$ de largo, una piedra angular de $12 \mathrm{~cm}$ de largo y una correa de cuero, y servía para ...descuartizar animales y cortar la carne en pequeños trozos, para trabajar asta $y$ varas para lanzas y arpones, los venablos y los aperos de presa, para descortezar árboles y preparar maderas necesarias para la canoa (Gusinde, 1986, p. 476). Otra herramienta era usada como un cuchillo o wiila, y para su confección se utilizaban las conchas o valvas de otro molusco, la navajuela (Ensis macha) o solen en lengua yagán, de unos $12 \mathrm{~cm}$ de largo y $3 \mathrm{~cm}$ de ancho. Este bivalvo se encuentra en playas arenosas poco profundas y se desenterraba con el fin de obtener sus conchas sin consumir su carne (Gusinde, 1986, p. 477).

Las conchas de molusco se utilizaban para recolectar y almacenar agua dulce. Para la colecta se usaban las grandes valvas de $M$. edulis chilensis y como recipiente perfecto la concha del caracol voluta, que en la actualidad hace referencia a dos especies, Odontocymbiola magallanica y Adelomelon ancilla (Gusinde, 1986, p. 555).

Las conchas de los moluscos fueron el componente central para la construcción de lo que hoy conocemos como "conchales". Las conchas se acumulaban formando montículos o "paredes" circulares alrededor de la choza o akar: Todos los desechos tales como conchas de almejas y lapas y los huesos eran arrojados afuera, cerca de la puerta, y con el correr del tiempo se forma un cerco protector de más de dos metros de alto alrededor de la hondonada donde vivía la gente (Bridges, 1952, p. 67). Orquera y Piana (1991) identifican las ventajas brindadas por estos montículos de conchas: como resguardo contra el viento; por estar el piso de las viviendas al mismo nivel de la superficie general, la percolación subsuperficial no se haría sentir tan marcadamente. Cuando los montículos eran anulares, las viviendas quedarían aisladas del escurrimiento de aguas superficiales de lluvia o fusión de la nieve; al estar los montículos constituidos principalmente por conchillas, retienen gran cantidad de aire acelerando el drenaje vertical y otorgando cierto grado de aislamiento térmico.

En conclusión, los moluscos habrían tenido un alto valor instrumental para el pueblo yagán por su uso como alimento, con fines estéticos y decorativos, elaboración de herramientas y material básico para la construcción de viviendas.

También se puede identificar un valor intrínseco a los invertebrados del intermareal en la cultura yagán. Los registros etnográficos dan cuenta de una capacidad de observación, emoción y reflexión que en ocasiones implicaban un sentido ético:

Aisladamente, se puede encontrar en las piedras de la costa, por debajo del 


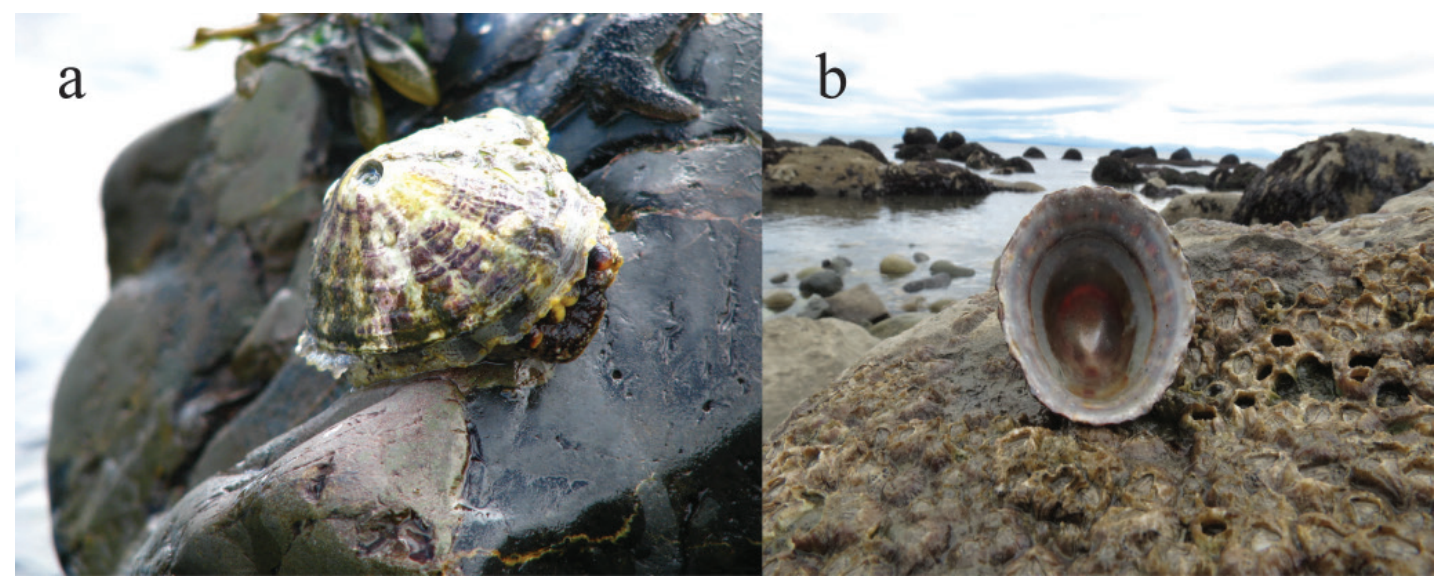

Fig. 5. Invertebrados marinos de isla Navarino asociados a narrativas de carácter ético del pueblo Yagán: a) Lapa (Fissurella spp.) desplazándose por el intermareal de bahía Róbalo; b) Maucho (Nacella spp) con el interior nacarado de la concha. (Fotografías Jaime Ojeda y Sebastián Rosenfeld).

nivel mínimo de bajamar, una fissurella extraordinariamente grande. Se la considera la dueña de la zona. En su proximidad todas las mujeres que alli recolectan frutos del mar deben permanecer en silencio y mostrar respeto, de no hacerlo, paiakakipa [nombre de la lapa en yagán], causa grandes remolinos de agua en concepto de castigo... El vocablo paiaka no es aquí un nombre propio, sino una denominación de carácter general; aquî tiene un significado especial. El agujero en el centro de la valva plana de esta fissurella es el ojo con el que la paiakakipa ve todo lo que ocurre a su alrededor (Gusinde, 1986, p. 1279) (Fig. 5a).

En la actualidad, algunas narrativas sobre moluscos continúan vivas en miembros de la comunidad yagán, como la artesana Julia González, quien nos relató historias que le fueron contadas por su madre, Úrsula Calderón. Algunos relatos tienen un sentido ético explícito:

Esta abuelita cuando veía gente acercarse a su choza, escondía todo su alimento para no compartirlo con el resto de la comunidad. Por esta razón, fue arrojada al mar en señal de castigo por su comportamiento. La historia de la abuelita mezquina fue plasmada con

9 El Regreso a la Madriguera (2011), documental realizado en el Parque Etnobotánico Omora, dirigido por Jaime Sepúlveda, producido por el Programa de Conservación una señal, que fue ilustrada con una mancha negra dentro de las nacellas o mauchos del intermareal. ${ }^{9}$

Este tipo de historias como la narrada por Julia González asociada al maucho (Nacella spp.), expresa cómo el pueblo yagán sanciona el comportamiento o hábitos como el egoísmo y promueve el sentido del respeto y empatía, valores vigentes hasta la actualidad. Estos registros etnográficos indican una valoración intrínseca de la biodiversidad y de la vida humana en comunidad.

Antecedentes filosóficos: ética ambiental. Tal como se señaló en la sección anterior, el análisis de los registros etnográficos y arqueológicos con la óptica de la ética ambiental contemporánea, permite identificar valores instrumentales e intrínsecos de la biodiversidad: el valor instrumental se encuentra en múltiples interacciones del pueblo yagán con macroalgas y moluscos y el valor intrínseco se asocia con registros de relación emocional y ética con seres humanos y no humanos en el entorno natural. Gusinde relata historias que eran narradas in situ a los niños en el propio hábitat de los personajes de las historias. De esta manera, el conocimiento tradicional del mundo natural y sus valores instrumentales $e$ intrínsecos se transmitían generación tras generación. El enfoque FILAC

Biocultural Subantártica (Universidad de Magallanes, Instituto de Ecología y Biodiversidad y Universidad de North Texas): httm://vimeo.com/31905600 
procura contribuir a que estas prácticas continúen, tal como se expone en el documental El Regreso a la Madriguera del realizador Jaime Sepúlveda.

Las valoraciones instrumental $e$ intrínseca han sido consideradas frecuentemente como opuestas (Rozzi, 1997). La primera se ha asociado a la escuela de conservación enfocada en el "uso racional de los recursos naturales" que hoy enfatiza los "servicios ecosistémicos". La economía ecológica ha desarrollado la valoración monetaria para bienes y servicios ecosistémicos de la biodiversidad a nivel mundial (Costanza et al. 1997, 2014). Una de las razones del nacimiento de estos enfoques ha sido otorgar mayor peso a los servicios ecosistémicos en las decisiones políticas (Rozzi, 1997). Sin embargo, es peligroso que la valoración de la biodiversidad se reduzca a una moneda de cambio, con una visión puramente utilitarista. El filósofo Mark Sagoff propone una transformación ética que requiere desligarse del paradigma económico, y que tampoco necesita de una crisis ambiental para estimular un cambio en nuestra relación con la naturaleza (Rozzi, 1997).

Proponemos que es necesario incluir ambas valoraciones, instrumental e intrínseca, de la biodiversidad. Un marco amplio de valoración permite incluir sentidos emocionales, racionales y evolutivos, todos ellos inherentes al ser humano. Las valoraciones se pueden vincular también a diversas formas de conocer el mundo natural (Rozzi, 1999). Esto lo podemos comprender si analizamos nuestra propia diversidad cognitiva y experiencia vivida. El neurobiólogo chileno Francisco Varela ${ }^{10}$ (2000) ha propuesto puntos clave para el futuro de las ciencias cognitivas, entre ellas la intersubjetividad ${ }^{11}$ o la empatía (ponerse en el lugar del otro), que muestran que la individualidad y la intersubjetividad no se oponen, sino que son complementarias. A partir del trabajo de Varela (2000) distinguimos cuatro fundamentos que pueden dar un punto de partida para complementar las líneas antropocéntrica (instrumental) y bio - o ecocéntrica (intrínseca):

10 Francisco Varela (1946-2001), biólogo chileno que investigó la neurociencia y ciencias cognitivas, fue el impulsor de la neuro-fenomenología y la fenomenología experimental. Paralelamente con su formación de biólogo, estudió filosofía en el Instituto Pedagógico Chileno. i) Todos los fenómenos cognitivos también son emocionales y afectivos.

ii) Debemos considerar el conocimiento enactivo, es decir, la cognición que producimos por el acto de manipular activamente, esto es mediante una conducta sensomotriz; por lo tanto, la experiencia humana parte de la experiencia vivida.

iii) Es a través del cuerpo de otro que establezco un vínculo con el otro, primero como organismo semejante al mío, pero también percibido como una presencia encarnada, lugar y medio en un campo experiencial.

iv) Esta doble dimensión del cuerpo (orgánico/vivido) es un aspecto esencial de la empatía.

Estos cuatros puntos enfatizan la necesidad de experiencias de campo para comprender los valores de la biodiversidad. Esta aproximación fenomenológica, es decir, basada en la experiencia, constituye un punto de encuentro entre las propuestas de Francisco Varela y de la FILAC. Las experiencias en el campo o hábitats con las comunidades de co-habitantes recobran la mirada sobre nuestra propia naturaleza humana, la reflexión de nuestra experiencia vivida (el hacer humano) y la empatía, donde florecen la emoción, el respeto por otros seres vivos (el otro no humano). Esta experiencia integra y trasciende a los valores instrumental e intrínseco.

Recientemente, Chan et al. (2016) mencionan que pocas personas toman decisiones personales basadas solamente en cómo las cosas poseen un valor inherente o satisfacen sus preferencias (valores intrínsecos e instrumentales, respectivamente). Ellas consideran cómo se relacionan con la naturaleza y con otros, incluyendo las acciones y los hábitos conducentes a una vida buena. En términos filosóficos, se trata de valores relacionales (preferencias, principios y virtudes asociados con las relaciones, tanto interpersonales como articuladas por políticas y normas sociales) (Chan et al. 2016). Las valoraciones son parte de nuestra biología cognitiva y de nuestra experiencia

11 Francisco Varela (2000), menciona que a temas como empatía e intersubjetividad se les puede dar un riguroso fundamente filosófico; son la punta del iceberg escondido de los últimos trabajos de Husserl. 
vivida, por ende los distintos tipos de valoraciones van de la mano con nuestras experiencias con el fenómeno de la naturaleza. Utilizamos el término fenómeno heredado de la teoría del conocimiento de Emanuel Kant, quien advierte que el intelecto no conoce las cosas tal como son en sí mismas (noúmeno), sino tal como nosotros las percibimos o representamos (fenómeno).

Para vincular las esferas cognitivas $y$ valorativas nos ayuda la filosofía kantiana, puesto que distingue en el proceso del conocer dos factores: la razón (forma) y las impresiones (materia) (Kant, 1787). El sujeto racional posee formas y categorías a priori que determinan las formas en que la naturaleza es percibida y conocida. Las impresiones se refieren a la materia que, a su vez, informa a la razón. Sin las impresiones, las formas y categorías de la razón permanecerían vacías. Por lo tanto, todo nuestro conocimiento surge con la experiencia que estimula sensaciones, a las que la razón dota de sentido.

Heredera de tradiciones filosóficas kantianas y post-kantianas, la FILAC investiga no solo qué conocemos (el objeto), sino también los procesos de cómo conocemos (el sujeto). A su vez, este proceso reflexivo vincula los fundamentos del conocer con sus consecuencias para la valoración, donde el objeto de observación pasa a ser un sujeto de observación. En esta integración se vinculan las ciencias cognitivas y la ética, y en este proceso conviven lo instrumental e intrínseco. Para ejemplificar cómo las valoraciones instrumentales $e$ intrínsecas están entretejidas en el conocer y habitar humano, podemos recurrir a dos ejemplos: (a) la historia yagán sobre la "fissurella extraordinariamente grande" registrada por Martin Gusinde (1986); y (b) un texto clásico de la ética ambiental "Pensando como una montaña" de Aldo Leopold (1949). ${ }^{12}$

(a) La historia natural yagán muestra que las principales fuentes de alimento eran proporcionadas en los hábitats costeros, y que involucraban los hábitos de recolección de moluscos realizado por las mujeres y los niños. Por lo tanto, ellos tenían una experiencia sensomotriz en sus búsquedas de alimento que ambientalista estadounidense que impulsó el desarrollo de permitía un conocimiento en-activo del hábitat y de una interdependencia ecológica (concepto antropocéntrico y valor instrumental). Pero también estando en este hábitat intermareal tenían experiencias de empatía con otros nohumanos, por ejemplo, cuando encontraban una lapa gigante del intermareal, a quien consideraban dueña del lugar, y por tanto debían tratar con respeto (concepto eco-céntrico y valor intrínseco).

(b) En "Pensando como una Montaña", Leopold relata una experiencia emotiva del encuentro con un otro no-humano, una loba, en un ecosistema montañoso del suroeste de EE.UU. de Norteamérica. En su vivencia personal como cazador de lobos, cuenta que:

En esos días no concebíamos dejar pasar oportunidad alguna para matar un lobo. Dentro de unos segundos lanzamos plomo a la manada... Alcanzamos a llegar donde la loba vieja a tiempo para ver en sus ojos moribundos un salvaje fuego verde que se extinguía. Alli me di cuenta, y desde entonces supe para siempre, que había algo nuevo para mi en esos ojos, algo que solamente ella y la montaña conocen.

En su encuentro cara a cara con la loba, Leopold nos sumerge en una emoción de empatía y con una valorización intrínseca de la vida de la loba en sí misma. Es notable que Leopold también reconoce la importancia del valor instrumental de los lobos y propone conceptos ecológicos que fundamentan que no es conveniente cazarlos indiscriminadamente. Concluye que:

el ranchero que limpia sus terrenos de lobos no se da cuenta que es él mismo quien debe realizar el trabajo de los lobos; esto es, que debe ir ajustando el número del ganado para mantener su pradera. El ranchero no ha aprendido a pensar como la montaña. Por eso tenemos erosión, y los ríos lavan los suelos llevándose el futuro al mar.

Estos relatos ilustran cómo los valores 
instrumentales e intrínsecos están entrelazados. Entrelazan también lo cognitivo y lo valórico, donde la experiencia de la empatía en el campo provee un fundamento para la conservación biocultural. Podemos identificar que las experiencias de diversos seres humanos en el Cabo de Hornos en Sudamérica y en la montaña en Norteamérica han estimulado valores intrínsecos e instrumentales que promueven la conservación la biodiversidad.

\section{Paso 2. Comunicación:}

Composición de la metáfora

Bosques Sumergidos del Cabo de Hornos

A partir de los resultados de la investigación ecológica, etnoecológica y filosófica, compusimos la metáfora "Los Bosques Sumergidos del Cabo de Hornos", que se refiere a los productores primarios del intermareal: los bosques de macroalgas. Al menos dos razones estimularon su composición:

i) Analogía ecológica: la región de canales y fiordos subantárticos de Magallanes incluye los bosques terrestres más australes del planeta, que a su vez incluyen bosques siempreverdes y deciduos. Los primeros están dominados por el coigüe de Magallanes (Nothofagus betuloides) y el canelo (Drymis winteri), mientras que los deciduos por lenga ( $N$. pumilio) y ñirre $(N$. antarctica) (Moore, 1983). Durante el otoño las hojas de las especies deciduas presentan vivos colores naranjo-rojizo y en invierno sus hojas caen sobre diferentes sustratos como suelo, rocas y ríos. En primavera, las hojas rebrotan con vivos colores verdes hasta el verano (Fig. 6). Esta dinámica foliar colorea los paisajes subantárticos de Magallanes. Con nuestra metáfora queremos comparar la dinámica foliar de los bosques terrestres mixtos con la dinámica estacional en los ambientes contiguos del "intermareal" y "submareal". Como señalamos antes, la biomasa del ensamble de algas disminuye en invierno y aumenta en verano (Fig. 6). Algunas especies conspicuas (e.g., Ceramium rubrum) son perennes y otras presentan un crecimiento estacional estival (e.g., Adenocystis utricularis y Pyropia columbina). Nuestra analogía relaciona los bosques terrestres y marino-costeros y su dinámica estacional. Esta metáfora comunica una biodiversidad exuberante, sumergida y que es poco percibida en la cultura cotidiana.

ii) Ecológica-histórica: Anteriormente mencionamos que, aunque la flora marina no era consumida directamente por el pueblo yagán, influía en su dieta y cultura a través de las redes de interacciones de las macroalgas con la fauna marina (e.g., moluscos herbivoros, crustáceos y aves) y el ser humano (Martial et al. 2007). Darwin también destacó la importancia ecológica del "alga gigante denominada Macrocystis pyrifera" e hizo la analogía entre "estas grandes selvas acuáticas del hemisferio meridional" y las "[selvas] terrestres de las regiones intertropicales". Nuestra metáfora hereda estos dos conceptos elaborados desde la antropología y la historia natural del siglo XIX en la región del Cabo de Hornos.

El nacimiento de esta metáfora revive el lenguaje ecológico que se expresa desde un lugar, al sur de Sudamérica, "el Cabo de Hornos". Desde aquí se invita a hacer un cambio de lentes para observar diferentes escalas de los ecosistemas, no solo observar los grandes bosques subantárticos terrestres, sino también observar la gran biodiversidad asociada a los "bosques de macroalgas" sumergidos bajo el mar austral.

\section{Paso 3. Actividades de Campo: \\ Ojo, Bucea Con Ojo}

Para observar, conocer, reflexionar y practicar la conservación biocultural de los "bosques sumergidos del Cabo de Hornos" diseñamos la actividad de campo Ojo, Bucea Con Ojo. Esta actividad enfatiza los "encuentros directos" con cohabitantes del intermareal y submareal $e$ invita a sumergirnos y explorar las costas subantárticas. Al menos tres razones estimularon su diseño:

i) Sensorial, nuestra percepción del mundo que nos rodea cambia bajo el mar; la percepción visual de las formas y colores "se distorsiona" respecto a cómo las observamos en los ambientes terrestres.

ii) Biología del conocer, el cambio en la experiencia visual nos estimula 


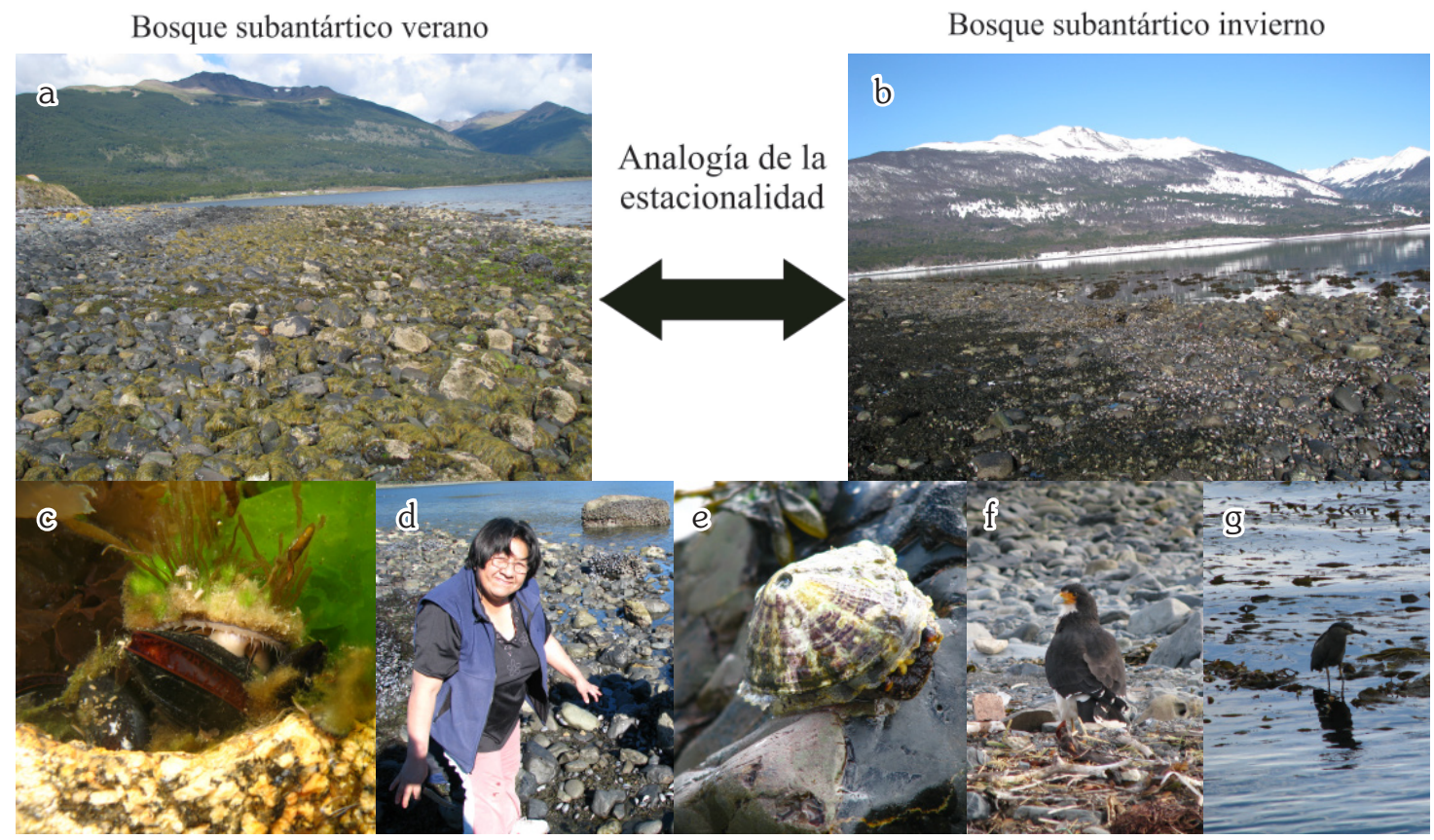

Fig. 6. Esquema de la analogía metafórica de los Bosques Sumergidos del Cabo de Hornos, representados en bahía Róbalo y cerro Róbalo, isla Navarino (5455'S; 67³9'O). (a) Vivos colores verdes en el follaje de los bosques terrestres y gran biomasa de algas intermareales (Pyropia columbina) durante verano. (b) Grandes áreas de bosques sin hojas coloreando el paisaje de color café oscuro, y disminución de la cobertura de algas intermareales durante el invierno.

Co-habitantes de los Bosques Sumergidos del Cabo de Hornos: (c) Pequeñas algas, bivalvos, crustáceos y poliquetos,

(d) humanos, la artesana yagán Julia González colectando moluscos (e) moluscos y (f, g) aves: carancho cordillerano,

(Phalcoboenus megalopterus) y huairavo (Nycticorax nycticorax). (Fotografías Jaime Ojeda).

a transformarnos en activos observadores de la diversidad biocultural marina. Como señala Humberto Maturana, el observar constituye una operación que demanda estar conscientes de estar observando algo en un momento dado (Maturana \& Porksen, 2008). El paso desde un ambiente terrestre a uno marino estimula la necesidad de observar con atención algo que se percibe de manera diferente a la forma cotidiana y que nos asombra con una biodiversidad que, por estar sumergida, es desconocida para la mayoría de los ciudadanos.

iii) Ecológica-Ética, la observación atenta genera una conexión perceptual y emocional con el ambiente marino: nos invita a la caracterización de los componentes, estructura y funciones (conceptos ecológicos), y nos estremece en la experiencia de cohabitar sumergidos. Esta experiencia estimula la reflexión acerca de los modos de co-habitar de los seres humanos ancestrales y actuales, incluyendo nuestro propio habitar con la naturaleza marina (ética). Esta reflexión es concordante con el marco conceptual de la ética biocultural que comprende y valora a los hábitats (dónde vivimos), los hábitos (cómo vivimos), los habitantes (quiénes somos) como una unidad ética y a la vez ecosistémica (Rozzi et al. 2008).

A partir de estas tres razones, la actividad Ojo, Bucea Con Ojo toma contenido biológico, ecológico y ético. La palabra Ojo se asocia al observar perceptual y cognitivo; Bucea se asocia al hábito humano arraigado en la historia de los canales subantárticos; Con Ojo enfatiza el respeto y la empatía que debemos tener con los seres vivos marinos. La actividad se realiza en el intermareal rocoso, con marea alta o baja, y las experiencias se han llevado a cabo en la bahía Róbalo asociadas a experiencias de inspiración artística, educación ambiental y turismo científico subantártico. Siempre se realiza con el apoyo de un asesor científico y, si está enfocada en educación 
ambiental, la actividad debe ir acompañada de un docente. Para contribuir a la identificación y aprecio in situ de la biodiversidad que se puede observar potencialmente, hemos elaborado una guía ilustrada (Contador et al. 2015; Ojeda et al. 2010), cuentos y fichas didácticas de la biodiversidad costera (Caballero \& Pizarro, 2012). Si la actividad está dirigida a niños, es recomendable realizarla con marea baja, el uso de botas de agua, bandejas y utilizar un cono con base de vidrio para observar la biodiversidad sumergida. Estas experiencias se han realizado con niños de educación parvularia, básica y diferencial de las escuelas de la Región de Magallanes. Si la experiencia está dirigida a jóvenes y adultos, es recomendable usar una máscara de buceo, snorkel y traje de buceo.

Con ambos grupos etarios (niños y jóvenesadultos), el número recomendado de participantes por grupo es de seis personas. Antes de ingresar al agua, la actividad comienza con el monitor y los participantes reuniéndose en círculo y abrazados.
El monitor cuenta un breve relato sobre la historia humana asociada al mar del Cabo de Hornos. Luego, entran al mar y se sumergen con la doble tarea de poner atención al cambio perceptualbiológico que se experimenta, y observar con calma, silencio y respeto la diversidad y belleza de los Bosques Sumergidos del Cabo de Hornos (Fig. 7a). Posteriormente a este primer "encuentro directo" con co-habitantes del intermareal y submareal, el monitor invita a explorar preferentemente cuatro zonas: (i) el ensamble de macroalgas intermareales, reflexionando sobre su estacionalidad (Fig. 7b); (ii) los bancos de choritos, reflexionando sobre su ausencia de estacionalidad $e$ importancia para la alimentación de los habitantes australes (Fig. 7c); (iii) las poblaciones de picorocos (Fig. 7d); (iv) los bosques sumergidos de macroalgas pardas (e.g., Lessonia vadosa y Macrocystis pyrifera) (Fig. 7e). Finalmente, dependiendo del enfoque de la actividad (educación ambiental, arte o turismo científico), el monitor invita a los
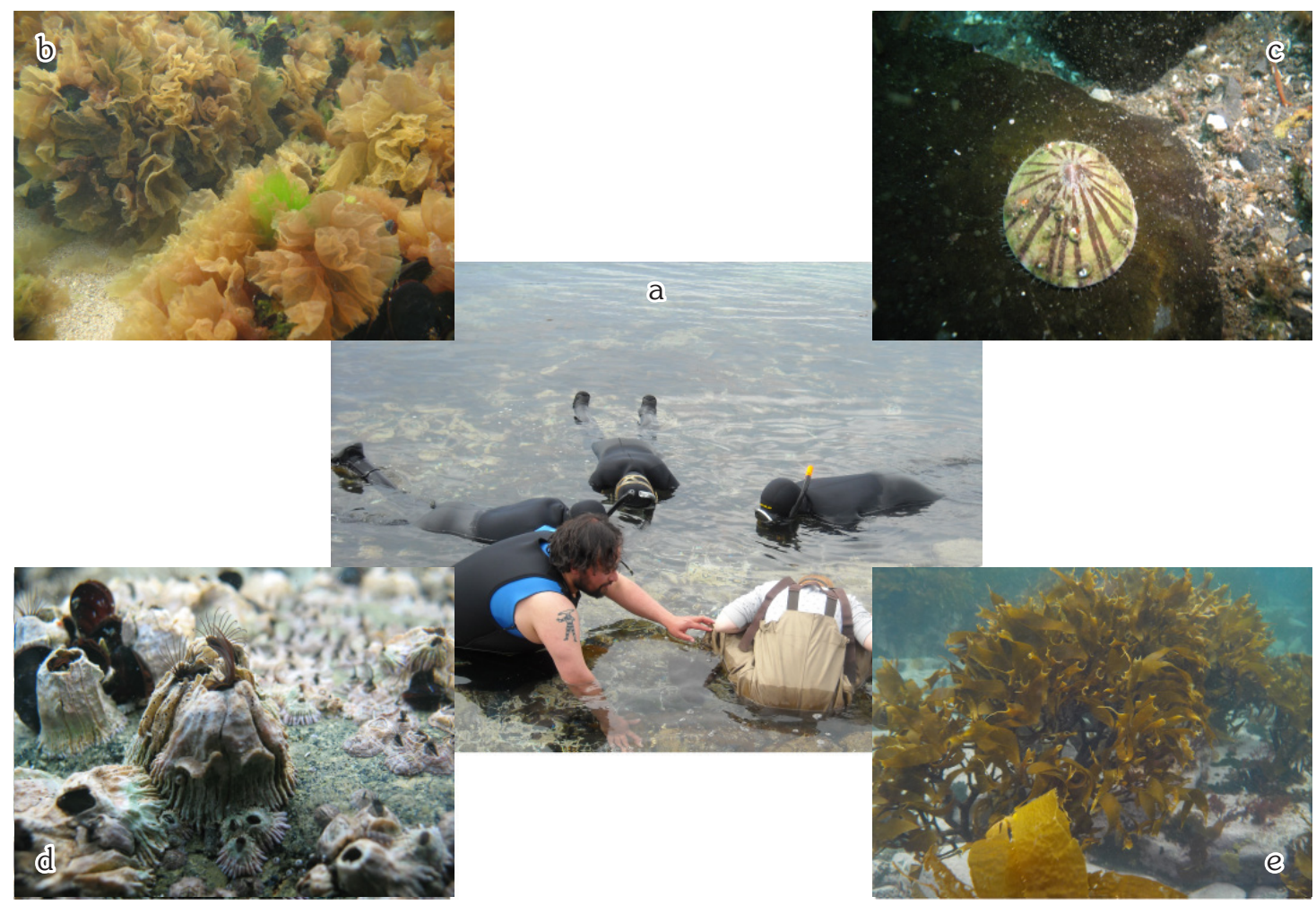

Fig. 7. Ojo, Bucea Con Ojo: actividad de educación, arte y turismo científico. (a) Jaime Ojeda guiando a estudiantes de Puerto Williams en su observación de la biodiversidad marina. (b) Vistas sumergidas de macroalgas intermareales (Pyropia spp.), (c) molusco herbívoro (Nacella flammea), (d) picorocos del intermareal, y (e) bosques de macroalgas (Lessonia vadosa). (Fotografías de Jaime Ojeda, Rodrigo Molina y Juan Rodríguez). 
participantes a crear un producto o realizar un rito en muestra de agradecimiento al mar. Por ejemplo, en la experiencia con educación ambiental se han creado poemas, esculturas, obras de títeres y trabajos científicos escolares.

En suma, en base a descubrimientos ecológicos en el intermareal generamos un lenguaje metafórico que orienta una reflexión sobre la diversidad biocultural marina en los ámbitos científico ecológico, etnoecológico y filosófico. En base a los descubrimientos y el lenguaje metafórico, hemos diseñado una actividad de campo orientada con un sentido ecológico y ético. Para desarrollar esta actividad se requiere, sin embargo, proteger un hábitat que conserve la biodiversidad intermareal.

Paso 4. Conservación in situ.

Diseño de un observatorio intermareal y submareal del Cabo de Hornos

Para conocer, re-descubrir y experimentar "encuentros directos" con la biodiversidad costeromarina junto a historias humanas entretejidas en el Cabo de Hornos, es esencial conservar hábitats, hábitos de vida y comunidades de co-habitantes. La conservación de estos hábitats es un imperativo ético y también una condición de posibilidad para disfrutar y convivir con la diversidad biocultural. Esta afirmación exige preguntarnos: ¿Por qué es necesario conocer para conservar? o ¿Por qué conservar para conocer?

En su libro El Árbol del Conocimiento, Humberto Maturana y Francisco Varela (2009, p. 162) afirman que el conocimiento del conocimiento obliga. Nos obliga porque al saber que sabemos no podemos negar lo que sabemos.... Este saber que sabemos, conlleva una ética que es inescapable y que no podemos soslayar. Aplicada a nuestro caso, esta reflexión sobre el conocer acerca de la existencia de otros co-habitantes en un hábitat nos interpela a no sólo ser un observador, sino también un protector de la biodiversidad marina. Esta interpelación es sinérgica con la FILAC cuya metodología demanda, en nuestro caso, proteger y habilitar espacios físicos para conocer, conservar y tener experiencias de co-habitar con algas, moluscos y otros seres (humanos y no-humanos) en la Reserva de la Biosfera Cabo de Hornos. Consecuentemente, procuramos promover el observar, conocer, valorar y realizar prácticas educativas que estimulen la empatía y re-experimenten encuentros directos con la diversidad marina y personas e historias humanas asociadas a ellas. Para ello, diseñamos un sendero interpretativo con cuatro estaciones que representan distintas facetas de la diversidad biológica y cultural del borde costero de Cabo de Hornos. Los relatos de cada estación se nutren de nuestra investigación ecológica, etnoecológica y filosófica.

Estación 1. Estacionalidad de las algas del intermareal. La formación de playas de bolones y cantos rodados del intermareal de la bahía Róbalo está asociada al transporte de rocas y su erosión durante los procesos de glaciación y deglaciación del Cuaternario. Aquí habita una alta diversidad de algas con una marcada estacionalidad entre invierno y verano. Por ejemplo, Pyropia columbina exhibe una fase macroscópica en el intermareal alto con máxima cobertura y biomasa en primaveraverano, y una fase microscópica (imperceptible al ojo humano) durante otoño-invierno. La fase microscópica se llama conchocelis porque se desarrolla al interior de conchas de moluscos. La fenología de esta alga se asocia con los hábitos de recolección artesanal y cocina tradicional del sur de Chile durante el verano.

Estación 2. Los choritos y su no estacionalidad, aspecto vital para el hombre ancestral. En las playas rocosas de bahía Róbalo los choritos (e.g., Mytilus edulis chilensis) son abundantes y cubren grandes extensiones del intermareal. Su tamaño es variable, desde 2 $\mathrm{mm}$ a $78 \mathrm{~mm}$ de longitud, y no presentan una estacionalidad en términos de su biomasa. Esta característica fue clave para la dieta del pueblo yagán; por lo tanto, su abundancia tenía gran relevancia para la selección de lugares de asentamiento en la región del Cabo de Hornos. La estación 2 permite reflexionar sobre valores bioculturales de estos moluscos: instrumental para la alimentación, estético-ornamental para la confección de collares, y material para la construcción de viviendas (conchales).

Estación 3. Narrativas yaganes sobre la biodiversidad intermareal. La abundancia de lapas y anémonas invita a comentar sobre la profunda conexión de la cultura yagán con su entorno 
marino, que inculcaba una actitud de respeto que se transmitía de generación en generación. Como señalamos antes, la historia de la lapa gigante del intermareal exigía a las personas mantener respeto y pasar en silencio; el encuentro con anémonas de mar (comúnmente conocidas como flor de mar) alegraba a los yagán puesto que se asociaba con el comienzo de la primavera. Las historias yagán expresan cómo la valoración ética de esta cultura por la biodiversidad intermareal también incluía un valor intrínseco, entretejido en relaciones de respeto y empatía. Los personajes de estas narrativas, lapas y anémonas, son abundantes en la bahía Róbalo y representan mensajeros de la historia biocultural ancestral y actual de las costas subantárticas que es necesario conocer y conservar.

Estación 4. Bosques Sumergidos del Cabo de Hornos. Los bosques sumergidos de Macrcystis pyrifera y otras macroalgas constituyen los principales productores primarios y forman complejos ecosistemas donde se alimentan moluscos, crustáceos, peces, aves y el hombre austral. Proveen también un hábitat crítico para el depósito de huevos de algunos moluscos y la provisión de algas para la construcción de nidos de aves. Los "bosques sumergidos del Cabo de Hornos" albergan una enmarañada red de interacciones ecológicas que es necesario observar in situ para comprender cabalmente su necesidad de conservación. Por consiguiente, en esta estación se invita al visitante a descubrir los bosques sumergidos mediante la actividad Ojo, Bucea Con Ojo.

\section{CONSIDERACIONES FINALES}

Al completar el ciclo de cuatro pasos de la Filosofía Ambiental de Campo, comprendemos que es una metodología circular del conocer. Se abren preguntas que conducen a nuevas investigaciones, metáforas, actividades guiadas de campo y acciones de conservación. Iniciamos nuestro ciclo con el descubrimiento del ensamble de macroalgas y su marcada dinámica estacional, que contrasta con los bancos de choritos (M. edulis chilensis) cuya biomasa no varía durante el año. Estos resultados ecológicos concordaron con antecedentes arqueológicos, históricos y etnográficos del pueblo yagán y su refinado conocimiento ecológico, gestado desde una experiencia vital inmersa en los hábitats costeros.
Los fenómenos cognitivos y la vida material estaban intimamente ligados a la búsqueda de alimentos, confección de herramientas y habitaciones, y al cultivo de una ética que abarcaba a la comunidad humana y más allá de ella, al conjunto de los seres. Esta ética generaba un profundo sentido de respeto y empatía. Nuestro estudio, organizado sobre la base de la FILAC, entreteje metodologías científicas y filosofías contemporáneas con una investigación y revaloración de hábitos culturales ancestrales y nos insta a conservar la diversidad biológica y cultural y sus interrelaciones en la Reserva de la Biosfera Cabo de Hornos. Nuestra propuesta incluye reactivar hábitos humanos entretejidos con el borde costero, mediante un conocer in situ del entorno costeromarino, prácticas de pensamiento analógico y comunicación poética y acciones de conservación biocultural para proteger los hábitats costeromarinos y reencontrarnos con los co-habitantes de los Bosques Sumergidos de Cabo Hornos mediante un nuevo hábito de bucear con ojo.

\section{AGRADECIMIENTOS}

Al equipo de trabajo del Parque Etnobotánico Omora y a la comunidad de Puerto Williams, especialmente a Cristóbal Pizarro, José González, Rodrigo Molina, Ximena Arango, Johanna Marambio y Rosaria Civitelli. J. Ojeda agradece a Mónica Villarroel, Ilda Gallardo y Cristián Suazo por su apoyo en la comprensión del valor cultural de la biodiversidad austral. Finalmente, agradecemos el apoyo del Instituto de Ecología y Biodiversidad (IEB) por el financiamiento de las becas de magister del proyecto ICM, Código P05-002 a J. Ojeda y Programa Basal PFB-23 a S. Rosenfeld. La preparación de este artículo ha contado con el apoyo de los proyectos CONICYT PFB- 23 y Apoyo a Centros Científicos y Tecnológicos de Excelencia con Financiamiento Basal CONICYT AFB170008. Finalmente, J.Ojeda agradece a Kelli Moses y Karen Chapple por las correciones en la escritura en ingles.

\section{BIBLIOGRAFÍA}

Aguilera, F., \& Tonko, J. (2011). Guía etnogeográfica del parque nacional Bernardo O'Higgins. Punta Arenas, La Prensa Austral. 
Anderson, M. J. (2005). PERMANOVA: a FORTRAN computer program for permutational multivariate analysis of variance. Auckland: University of Auckland, New Zealand, Department of Statistics.

Benedetti-Cecchi, L., \& Cinelli, F. (1997). Spatial distribution of algae and invertebrates in the rocky intertidal zone of the Strait of Magellan: are patterns general? Polar Biology, 18, 337-343.

Bridges, L. (1952). El último confín de la tierra. Buenos Aires: EMECÉ Editores S.A.

Broitman, B. R., Véliz, F., Manzur, T., Wieters, E. A., Finke, G. R., Fornes, P. A., Valdivia, N., \& Navarrete, S. A. (2011). Geographic variation in diversity of wave exposed rocky intertidal communities along central Chile. Revista Chilena de Historia Natural, 84, 143154.

Butorovic, N. (2009). Resumen meteorológico año 2008 estación Jorge C. Schythe $\left(53^{\circ} 08^{\prime} \mathrm{S} ; 70^{\circ} 53^{\prime} \mathrm{W} ; 6\right.$ M.S.N.M.). Anales del Instituto de la Patagonia, 37, 133-140.

Caballero, P., \& Pizarro, M. (2012). Diversicuentos. Cuentos infantiles sobre la diversidad biocultural subantártica. Punta Arenas: Ediciones Universidad de Magallanes.

Callicott, J. B. (1989). In Defense of the Land Ethic: Essays in Environmental Philosophy. Albany: State Univ. N.Y. Press.

Camus, P. A. (2001). Biogeografía marina de Chile continental. Revista Chilena de Historia Natural, 74, 587-617.

Cárdenas, C. A., Cañete, J. I., Oyarzún, S., \& Mansilla, A. (2007). Podding of juvenile king crabs Lithodes santolla (Molina, 1782) (Crustacea) in association with holdfasts of Macrocystis pyrifera (Linnaeus) C. Agardh, 1980. Investigaciones Marinas, 35(1), 105-110.

CEAZA-MET. (2010). Red de sensores meteorológicos. Centro de Estudios Avanzados en Zonas Áridas (CEAZA) [ULSUCN-INIA]. Recuperado en: httm://www.ceazamet.cl

Chan, K. M., Balvanera, P., Benessaiah, K., Chapman, M., Diaz, S., Gómez-Baggethun, E., Gould, R.,... Luck, G. W. (2016). Why protect nature? Rethinking values and the environment. Proceedings of the National Academy of Sciences, 113, 1462-1465.

Clarke, K. R. (1993). Non-parametric multivariate analysis of changes in community structure. Australian Journal of Ecology, 18, 117-143.

Constanza, R., Hart, M., Posner, S., \& Talberth, J. (2009). Beyond GDP: The need for new measures of progress. Boston: Boston University.

Contador, T., Rosenfeld, S., Ojeda, J., \& Kennedy, J. H. (2015). Historia natural de los invertebrados acuáticos del
Cabo de Hornos. Punta Arenas: Editorial Universidad de Magallanes.

Cornejo, S. (1996). Reporte preliminar de macroalgas presentes en bahía Laredo, estrecho de Magallanes. Anales del Instituto de la Patagonia, 24, 87-95.

Costanza, R., D’Arge, R., De Groot, R., Farber, S., Grasso, M., Hannon, B., Limburg, K., Naeem, S., ... Van den Belt, M. (1997). The value of the world's ecosystem services and natural capital. Nature, 387, 253-260.

Costanza, R., de Groot, R., Sutton, P., van der Ploeg, S., Anderson, S. J., Kubiszewski, I., Farber, S. \& Turner, R. K. (2014). Changes in the global value of ecosystem services. Global Environmental Change, 26, 152158.

Darwin, C. (1939).Voyages of the adventure and beagle. Vol III, London, Henry Colburn, Great Marlborough Street.

Dayton, P. K. (1985). The structure and regulation of some South American Kelp Communities. Ecological monographs, 55, 447-468.

Díaz, H. (2006). La metáfora en la definición científica. En M. di Stefano (Coord.), Metáforas en uso (158 pp). Buenos Aires: Editorial Biblos.

Dillehay, T. D., Ramírez, C., Pino, M., Collins, M. B., Rossen, J,. \& Pino-Navarro, J. D. (2008). Monte Verde: seaweed, food, medicine, and the peopling of South America. Science, 320, 784-786.

Emperaire, J. (1963). Los nómades del mar. Versión española. Santiago de Chile: Ediciones de la Universidad de Chile.

Fiore, D., \& Varela, M. L. (2009). Memorias de papel: Una arqueología visual de las fotografías de pueblos originarios fueguinos. Buenos Aires: Editorial Dunken.

Guevara, S., \& Laborde, J. (2008). The landscape approach: Designing new reserves for protection of biological and cultural diversity in Latin America. Environmental Ethics, 30, 251-262.

Gunnarsson, K., \& Ingólfsonn, A. (1995). Seasonal changes in the abundance of intertidal algae in Southwestern Iceland. Botánica Marina, 38, 69-77.

Gusinde, M. (1951). Hombres primitivos en la tierra del fuego: De investigador a compañero de tribu. Sevilla, Publicaciones de la escuela de estudios hispanoamericanos

Gusinde, M. (1986). Los indios de Tierra del Fuego. Tomo Il Los Yámanas, 1478pp. CAEA, 3 Vols. Buenos Aires, Argentina.

Guzmán, L., \& Ríos, C. (1981). Estructura de macroorganismos de una playa de bloques y cantos de isla Wollaston, archipiélago del Cabo de Hornos. Anales del Instituto de la Patagonia, Chile 12, 257-271. 
Guzmán, L., Pacheco, H., Pizarro, G., \& Alarcón, C. (2002). Alexandrium catenella y veneno paralizante de los mariscos en Chile. En E. A. Sar, M. E. Ferrario \& B. Reguera (Eds.), Floraciones algales nocivas en el cono sur Americano (311 pp). Madrid: Instituto Español de Oceanografía.

Hulton, N. R. J., Purves, R. S., Mcculloch, R. D., Sugden, D. E., \& Bentley, M. J. (2002). The Last Glacial Maximum and deglaciation in southern South America. Quaternary Science Reviews, 21, 233-241.

Hyades, P., \& Deniker, J. (2007). Etnografía de los indios Yaghan en la misión científica del Cabo de Hornos, 1882-1883 (Vol. 245). Punta Arenas: Universidad de Magallanes.

Kant, I. (1787). Crítica de la razón pura. Edición digital basada en la edición de Madrid, Librería General de Victoriano Suárez.

Koppers, W. (1997). Entre los fueguinos. Punta Arenas: Ediciones Universidad de Magallanes.

Langley, S., Guzman, L., \& Ríos, C. (1980). Aspectos dinámicos de Mytilus chilensis (Hupé, 1840) en el estrecho de Magallanes. I. Distribución, densidad y disposición espacial en el intermareal. Anales del Instituto de la Patagonia, Serie Ciencias Naturales, 11, 319-332.

Lefèvre, C. (1993). Las aves en los yacimientos del archipiélago del Cabo de Hornos y del seno Grandi. Anales Instituto de la Patagonia, Serie Ciencias Sociales y Historia, 22, 123-135.

Legoupil, D. (1993). El archipiélago del Cabo de Hornos y la costa sur de la isla Navarino: Poblamiento y modelos económicos. Anales Instituto de la Patagonia, Serie Ciencias Sociales y Historia, 22, 101-121.

Leopold, A. (1949). Thinking like a Mountain. A Sand County Almanac and Sketches Here and There. New York, Oxford University Press.

Lotze, H. K., Lenihan, H. S., Bourque, B. J., Bradbury, R. H., Cooke, R. G., Kay, M. C., Kidwell, S. M.,... \& Jackson, J. B. C. (2006). Depletion, degradation, and recovery potential of estuaries and coastal seas. Science 312, 1806.

Mansilla, A., Ávila, M., Cáceres, J., Palacios, M., Navarro, N., Cañete, I., \& Oyarzún, S. (2009). Diagnóstico Bases Biológicas Explotación Sustentable Macrocystis pyrifera, (Huiro), XII Región Código BIP N 30060262 0. 345pp. Gobierno Regional de Magallanes y Antártica Chilena. Informe de Proyecto, Universidad de Magallanes, Chile.

Martial, L. F., Hyades, P., \& Deniker, J. (2007). Etnografía de los indios yaghan en la misión científica del Cabo de Hornos 1882-1883. En D. Legoupil \& A. Prieto (Eds.), (332 pp). Punta Arenas: Ediciones Universidad de Magallanes-Instituto Francés de Estudios Andinos.

Maturana, H., \& Porksen, B. (2008). Del ser al hacer. "Los orígenes de la biología del conocer". Buenos Aires. Ediciones GRANICA.

Maturana, H., \& Varela, F. (2009). El árbol del conocimiento. Santiago, Editorial Universitaria.

Mittermeier, R. A., Mitterneier, C. G., Brooks, T. M., Pilgrim, J. D., Konstant, W R., Da Fonseca, G. A. B., \& Kormos, C. (2003). Wilderness and biodiversity conservation. PNAS, 100, 10309-10313.

Molina, W. C. (2011). Identidad regional en Magallanes, sus expresiones simbólicas y territoriales. Magallania, 39, 59-69.

Moore, D. M. (1983). Flora of Tierra de Fuego. Anthony Nelson, England, Missouri Botanical Garden.

Mutschke, E., Ríos, C., \& Montiel, A. (1998). Situación actual de la macrofauna presente en el intermareal de bloques y cantos de Bahía Laredo, Estrecho de Magallanes. Anales del Instituto de la Patagonia, Serie Ciencias Naturales 26, 5-29.

Ojeda, J., Contador, T., Rosenfeld, S., Anderson, C. B., Mansilla, A., \& Kennedy, J. H. (2010). Guía para la identificación de los invertebrados marinos y dulceacuícolas de la Reserva de Biósfera Cabo de Hornos. Punta Arenas: Ediciones Universidad de Magallanes.

Ojeda, J, Contador, T., Medina, Y., Pizarro, J. C., Molina R, Mansilla, A., Kennedy, J. H.,... \& Rozzi, R. (2013). Ecoturismo con lupa: Para apreciar la biodiversidad subantártica en la Reserva de Biósfera Cabo de Hornos. Ciencia en el Austro, 6, 51-66.

Ojeda, J., Rosenfeld, S., Marambio, J., Rozzi, R., \& Mansilla, A. (2014). Seasonal and spatial patterns of intertidal molluscs diversity of Róbalo Bay, Beagle Channel, Biosphere Reserve Cape Horn, Chile. Revista de Biología Marina y Oceanografía, 49, 493-509.

Ojeda, J., Marambio, J., Rosenfeld, S., Contador, T., Rozzi, R., \& Mansilla, M. (En revisión). Temporal changes of macroalgae assemblage on the rocky shores of the Cape Horn Biosphere Reserve, Sub-Antarctic, Chile.

Orquera L. A., \& Piana E. L. (2002). Composición de conchales de la costa del canal Beagle (Segunda Parte). Relaciones de la Sociedad-Argentina de Antropología, XXVI, 345-368.

Orquera, L. A., \& Piana, E. L. (1991). La formación de los montículos arqueológicos de la región del canal Beagle. Runa, XIX, 59-82. 
Orquera, L. A. (2000). El consumo de moluscos por los canoeros de extremo sur. Relaciones de la Sociedad Argentina de Antropología. Buenos Aires.

Orquera, L. A., Piana, E. L., Fiore, D., \& Zangrando, A. F. (2012). Diez mil años de fuegos, arqueología y etnografía del fin del mundo. Buenos Aires: Editorial Dunken.

Palmer, C. (2013). Contested Frameworks in Environmental Ethics. En R. Rozzi, S. T. A. Pickett, C. Palmer, J. J. Armesto, J. B. Callicott (Eds.), Linking ecology and ethics for a changing world: values, philosophy and action (pp. 191-206). Dodrecht, Netherlands: Springer.

Ríos, C., \& Mutschke, E. (1999). Community structure of intertidal boulder-cobble fields in the Straits of Magellan, Chile. Scientia Marina 63(Supl. 1), 193-201.

Roberts, C. M. \& Hawkins, J. P. (1999). Extinction risk in the sea. Trends in Ecology \& Evolution 14, 241-246.

Rosenfeld, S., Ojeda, J., Hune., M, Mansilla, A., \& Contador, T. (2014). Egg masses of the Patagonia squid Dorytheutis (Amerigo) gahi attached to giant kelp (Macrocystis pyrifera) in the sub-Antarctic ecoregion. Polar Research, http://dx.doi.org/10.3402/polar. v33.21636.

Rozzi, R. (1997). Hacia una superación de la dicotomía biocentrismo-antropocentrismo. Revista Ambiente y Desarrollo, XIII(3), 80-89.

Rozzi, R., (1999). The reciprocal links between evolutionaryecological sciences and environmental ethics. BioScience, 49(11), 911-921.

Rozzi, R. (2012). Biocultural ethics: Recovering the vital links between the inhabitants, the habits, and hábitats. Environmental Ethics, 34, 27-50.

Rozzi, R. (2013). Biocultural Ethics: From biocultural homogenization toward biocultural conservation. (2013). En R. Rozzi, S. T. A. Pickett, C. Palmer, J. J. Armesto \& J. B. Callicott (Eds.), Linking ecology and ethics for a changing world: values, philosophy and action. Springer Netherlands, DOI 10.1007/978-94007-7469-8

Rozzi, R., Feinsinger, P., \& Riveros, R. (1997). La Enseñanza de la Ecología en el Entorno Cotidiano. Módulo de Ciencias Naturales. Santiago de Chile: Ministerio de Educación de Chile.

Rozzi, R., Massardo, F., Mansilla, A., Anderson, C. B., Berghofer, A., Mansilla, M. O., Gallardo, M. R.,... \& Barros, E. (2007). La Reserva de Biosfera Cabo de Hornos: un desafío para la conservación de la biodiversidad e implementación del desarrollo sustentable en el extremo austral de América. Anales del Instituto de la Patagonia, 35, 55-70.

Rozzi, R., Arango, X., Massardo, F., Anderson, CB., Heidinger, K., \& Moses, K. (2008). Filosofía Ambiental de Campo y conservación biocultural: El programa educativo del Parque Etnobotánico Omora. Environmental Ethics, 30, 325-336.

Rozzi, R., Anderson, C. B., Pizarro, J. C., Massardo, F., Medina, Y., Mansilla, A., Kennedy, J. K., ... \& Kalin, M. T. (2010). Filosofía ambiental de campo y conservación biocultural en el Parque Etnobotánico Omora: Aproximaciones metodológicas para ampliar los modos de integrar el componente social ("S") en Sitios de Estudios Socio-Ecológicos a Largo Plazo (SESELP). Revista Chilena de Historia Natural, 83, 27-68.

Rozzi, R., Armesto, J. J., Gutierrez, J., Massardo, F., Likens, G., Anderson, C. B., Poole, A.,... \& Kalin, M. T. (2012). Integrating ecology and environmental ethics: Earth stewardship in the southern end of the Americas. BioScience 62, 226-236.

Sandler, R. (2012) Intrinsic value, ecology and conservation. Nature education knowledge, 3(10), 4.

Santana, A., Porter, C., Butorovic, N., \& Olave, C. (2006). Primeros antecedentes climatológicos de Estaciones Automáticas (AWS) en el canal Beagle, Magallanes, Chile. Anales del Instituto de la Patagonia, Serie Ciencias Naturales 34, 5-20.

Santelices, B., \& Marquet, P. A. (1998). Seaweeds, latitudinal diversity patterns, and Rapoport's Rule. Diversity and Distributions 4, 71-75.

Santelices, B., \& Ojeda, F. P. (1984). Effects of canopy removal on the understory algal community structure of coastal forests of Macrocystis pyrifera from southern South America. Marine Ecology Progress Series 14, 165173.

Spalding, M. D., Fox, H. E., Allen, G. R., Davidson, N., Ferdaña, Z. A., Finlayson, M., Halpern, B. S.,... \& Robertson, J. (2007). Marine ecoregions of the world: a bioregionalization of coast and shelf areas. BioScience, 57, 573-583.

Sepúlveda, J. (2012). El Viaje Invisible. Ecoturismo con Lupa. Video. University of North Texas Press.

SHOA. (2008). Servicio Hidrográfico y Oceanográfico de la Armada de Chile. Disponibilidad de datos diarios de mareas de sicigia y cuadratura para Puerto Williams, isla Navarino, Chile. [en línea] <httm://www.shoa.cl>.

Silva, N., \& Calvete, C. (2002). Características oceanográficas físicas y químicas de canales australes chilenos entre el Golfo de Penas y el Estrecho de Magallanes (Crucero CIMAR-FIORDOS 2). Ciencia y tecnología del mar, 
Chile. 25, 23-88.

Soto, E., Báez, P., Ramírez, M. E., Letelier, S., Naretto, J., \& Rebolledo, A. (2012). Biotopos marinos intermareales entre Canal Trinidad y Canal Smyth, Sur de Chile. Revista de Biología Marina y Oceanografía 47, 177-191.

Valdovinos, C., Navarrete, S. A., \& Marquet, P. A. (2003).
Mollusk species diversity in the Southeastern Pacific: Why are there more species towards the pole? Ecography, 26, 139-144.

Varela, F. (2000). Fours batons for the future of cognitive science. En B. Wiens (Ed.), Envisioning knowledge (221-298 pp). Dumont, Cologne. 
